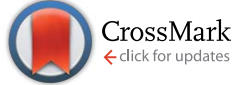

Cite this: J. Anal. At. Spectrom., 2015 30, 599

Received 30th October 2014

Accepted 2nd January 2015

DOI: $10.1039 / c 4 j a 00372 a$

www.rsc.org/jaas

\section{Thermodynamic and experimental study of the degradation of the red pigment mercury sulfide}

\author{
Marie Radepont, ${ }^{\text {abc }}$ Yvan Coquinot, ${ }^{d}$ Koen Janssens, ${ }^{a}$ Jean-Jacques Ezrati, ${ }^{d}$ Wout de \\ Nolf ${ }^{a}$ and Marine Cotte ${ }^{b c e}$
}

\begin{abstract}
The red pigment mercury sulfide, called cinnabar or vermilion, is well known to suffer from an alteration giving rise to a grey, grey-white or black color at the surface of degraded works of art. This phenomenon can dramatically affect the esthetical value of artworks. This work aims at assessing the factors (light, halides) influencing the instability of red mercury sulfide and understanding (by combining thermodynamic and experimental approaches) the chemical equilibria governing the formation and evolution of the different degradation compounds. From the thermodynamic study of the $\mathrm{Hg}-\mathrm{S}-\mathrm{Cl}-$ $\mathrm{H}_{2} \mathrm{O}$ system, it was concluded that $\mathrm{Hg}(0), \mathrm{Hg}_{3} \mathrm{~S}_{2} \mathrm{Cl}_{2}$, and $\mathrm{Hg}_{2} \mathrm{Cl}_{2}$ can be formed from the reaction of $\alpha$ $\mathrm{HgS}$ with $\mathrm{ClO}_{(\mathrm{g})}$. In the second part, the artificial ageing experiments presented were carried out on model samples following the conditions assessed in the first part, in order to reproduce natural ageing observed on red mercury sulfide. Similarly to degradation compounds detected on original works of art, mercury chlorine compounds such as calomel $\left(\mathrm{Hg}_{2} \mathrm{Cl}_{2}\right)$ and corderoite $\left(\alpha-\mathrm{Hg}_{3} \mathrm{~S}_{2} \mathrm{Cl}_{2}\right)$ were identified on the surface of $\alpha$-HgS model samples, when exposed to light and a sodium hypochlorite solution. Sulfates were detected as well, and more particularly gypsum $\left(\mathrm{CaSO}_{4} \cdot 2 \mathrm{H}_{2} \mathrm{O}\right)$ when $\mathrm{Ca}$ was originally present in the model sample. The relationship between color and composition is discussed as well.
\end{abstract}

\section{Introduction}

Red mercury sulfide, called cinnabar in its natural form, was extracted from several deposits and by many cultural communities around the world since the Neolithic period. Cinnabar has been used mainly as a pigment but also as a cosmetic or a medicine. This mineral species occurs most frequently as small crystals of micro- to millimetric size in siliceous rocks such as sandstone or quartzite, and sometimes in association with carbonate crystallizations. The $\alpha$-HgS ore was usually prepared as follows: after crushing in an iron mortar, the powder was heated and washed to remove impurities, giving the material a vivid red color. From the $8^{\text {th }}$ century, a synthetic process (called "dry process") was adopted, involving the heating of a mixture of mercury and sulfur to $580{ }^{\circ} \mathrm{C}$, and leading to the same component $(\alpha-\mathrm{HgS})$ but called vermilion in this case. Since the $17^{\text {th }}$ century, the "wet process" was used for the manufacture of vermilion, consisting in mixing the initial products in an

\footnotetext{
${ }^{a}$ Department of Chemistry, University of Antwerp, Groenenborgerlaan 171, B-2020, Antwerp, Belgium. E-mail: marie.radepont@gmail.com

${ }^{b}$ UPMC Univ Paris 06, UMR 8220, Laboratoire d'archéologie moléculaire et structurale, LAMS, F-75005, Paris, France

${ }^{c}$ CNRS, UMR 8220, LAMS, F-75005, Paris, France

${ }^{d}$ Centre de Recherche et de Restauration des Musées de France, Palais du Louvre, 14 quai François Mitterrand 75001, Paris, France

${ }^{e}$ European Synchrotron Radiation Facility, 71 avenue des Martyrs 38000, Grenoble, France
}

ammonium or potassium sulfide solution in order to decrease the heating temperature. ${ }^{1}$

The photosensitivity of red mercury sulfide is already known since antiquity and was mentioned by Pliny the Elder. ${ }^{2}$ Previous investigations found that some cinnabar samples show a peculiar tendency to turn black upon exposure to light. ${ }^{3}$ Indeed, in mineralogical collections some of them can turn black in a few days while others are still red after several centuries when exposed to artificial or sun light. Experiments also showed that the kinetics of the alteration induced by light depend on the type of mercury sulfide studied. Vermilion produced by the "wet process" appears to darken faster than the one from the "dry process" and the synthetic forms generally degrade faster than those formed in nature (cinnabar). ${ }^{4}$ However, the origin of the blackening of the latter type of red mercury sulfide has never been identified and no degradation compounds have been detected yet. Next to light, the presence of halides also is required for the degradation, leading to the formation of different compounds. Davidson et al. made the following observation: mercury sulfide suspended in aqueous potassium iodide exposed to light led, after washing and drying at $80^{\circ} \mathrm{C}$, to a black powder. ${ }^{5}$ From the beginning of the $21^{\text {st }}$ century, chlorine-containing compounds were suspected to be related to the color change as it was shown that some photosensitive cinnabar contains chlorine whereas the non-photosensitive equivalent does not. ${ }^{6}$ 
Degradation of red mercury sulfide (cinnabar/vermilion) in works of art has been studied by several research groups in the last twenty years. Metacinnabar $(\beta-\mathrm{HgS})$, the cubic form of mercury sulfide showing a black color, was long thought to be responsible for the dark color of debased cinnabar. ${ }^{5,7}$ However, $\alpha$-HgS needs a temperature higher than $370{ }^{\circ} \mathrm{C}$ to be converted into $\beta$-HgS. ${ }^{8,9}$ More recently, as it is the case for geological samples, the main studies on this pigment identified light and chlorine as two of the main factors inducing red mercury sulfide alteration. ${ }^{1,10-16}$ Chlorine compounds were identified on degraded works of art by multiple analytical techniques such as secondary ion mass spectroscopy (SIMS), ${ }^{12}$ Raman spectroscopy, ${ }^{13} \mathrm{X}$-ray fluorescence (XRF) and X-ray absorption near edge structure (XANES)..$^{14,15}$ In our previous study, ${ }^{16}$ all the samples (taken from degraded original works of art) analyzed by X-ray diffraction (XRD) showed the same type of chlorinated compounds, i.e. calomel $\left(\mathrm{Hg}_{2} \mathrm{Cl}_{2}\right)$ and $\mathrm{Hg}_{3} \mathrm{~S}_{2} \mathrm{Cl}_{2}$ in two different phases: corderoite $\left(\alpha-\mathrm{Hg}_{3} \mathrm{~S}_{2} \mathrm{Cl}_{2}\right)$ and kenhsuite $\left(\gamma-\mathrm{Hg}_{3} \mathrm{~S}_{2} \mathrm{Cl}_{2}\right)$. These compounds were found to be situated in three different layers, the original $\alpha-\mathrm{HgS}$ being covered by $\mathrm{Hg}_{3} \mathrm{~S}_{2} \mathrm{Cl}_{2}$ which in its turn is coated by a layer of $\mathrm{Hg}_{2} \mathrm{Cl}_{2}$; the latter compound appears to be situated on top of the original surface of the pictorial layer. ${ }^{16}$ Next to the cultural heritage field, mercury chlorine compounds such as corderoite and calomel were identified in soils in the neighborhood of chlor-alkali plants. ${ }^{17}$ This study also showed the presence of amorphous $\mathrm{Hg}, \mathrm{S}, \mathrm{Cl}$ compounds in the same soils.

Keune et $a l .{ }^{12}$ proposed that (a) the darkening of red mercury sulfide induced by light and (b) the formation of $\mathrm{Hg}$ and $\mathrm{Cl}-$ containing compounds are two separate steps of the degradation process: they suggested that chlorine acts as a catalyst in the first step, which consists in the light-induced transformation of $\mathrm{HgS}$ into $\mathrm{Hg}(0)$ and $\mathrm{S}(0)$; then mercury reacts with chlorine in multiple steps to form various mercury chlorine compounds. In a recent study, Da Pieve et al. ${ }^{18}$ used for the first time a combination of XRD and theoretical spectroscopy to propose a model for the pathway of the degradation of mercury sulfide. Indeed, they showed that theoretically, under the influence of sunlight or museum lamps and chlorine, the red pigment can be transformed into unstable corderoite which transforms again into calomel.

The origin of chlorine is of high importance since it will determine the way of storing, cleaning and consolidating works of art. Sources both natural or related to human activities should be considered. In the atmosphere, chlorine can be found as various gaseous species originating from the sea for one large part, from volcanoes for a smaller part and from industrial activities. The total concentration of chlorine in the atmosphere in coastal areas was evaluated to be between 6 and $20 \mu \mathrm{g} \mathrm{m}^{-3}$ in 1974 in Japan, ${ }^{19}$ and more recently up to $5 \mu \mathrm{g} \mathrm{m}{ }^{-3}$ anywhere in Japan, even far inland. ${ }^{20}$ Next to these sources, chlorine could also be present in the materials of the works of art themselves, such as varnishes, binders or protein based glues. ${ }^{16,21}$ Specific actions of curators may also be responsible for the presence of chlorine in some works of art by the use of Cl-containing adhesives and consolidants. Moreover, chlorinated solutions such as carbon tetrachloride $\mathrm{CCl}_{4}$, has been used in the past by curators to treat wood supports against insect invasion. ${ }^{22,23}$ In the Louvre museum, several paintings containing mercury sulfide showing grey or black crusts at the surface of the red areas are reported to have been treated with $\mathrm{CCl}_{4}$ in the 1960 's. ${ }^{24-27}$ Previous analyses performed on these works of art did not include any information on the presence of chlorine compounds, however. Chlorine could also come from cleaning products used to sterilize floors in museums, such as solutions of sodium hypochlorite, which induce the presence of this element in museum indoor atmosphere.

Next to being of great relevance for conservation and restoration of works of art, the understanding of the formation and the stability of mercury compounds, and in particular of $\mathrm{HgS}$, is also of high concern in the field of environment sciences. The $\mathrm{Hg}-\mathrm{S}-\mathrm{Cl}-\mathrm{H}_{2} \mathrm{O}$ system has been studied in order to identify the stability domains of such compounds..$^{28-30}$ The diagram presented by Brandon et al. ${ }^{28}$ showed that at high $\mathrm{pH}(>8)$ and potential values below $0.2 \mathrm{~V}$, metallic mercury is predicted to be formed from $\mathrm{HgS}$. $\mathrm{Hg}_{2} \mathrm{SO}_{4}$ and $\mathrm{HgSO}_{4}$ also appeared to be stable at low $\mathrm{pH}$. In this study, chlorine ions were considered as a neutral compound and not as a reactant contrarily to the present investigation. Svensson et al. ${ }^{29}$ constructed a Pourbaix diagram for mercury species and showed that mercury chloride compounds $\left(\mathrm{Hg}_{2} \mathrm{Cl}_{2}\right.$ and $\left.\mathrm{HgCl}_{2}\right)$ are formed in aerobic conditions (at high potential) and at $\mathrm{pH}$ below 10. Parks et al. ${ }^{30}$ studied the formation of corderoite $\left(\alpha-\mathrm{Hg}_{3} \mathrm{~S}_{2} \mathrm{Cl}_{2}\right)$. To estimate the free energy of formation $\left(\Delta G_{\mathrm{f}}^{0}\right)$ of this compound, they considered the experimental study by Carlson, ${ }^{31}$ yielding the following equations:

$$
\begin{gathered}
\mathrm{HgS}_{(\mathrm{s})}+2 \mathrm{HCl}=\mathrm{HgCl}_{2(\mathrm{~g})}+\mathrm{H}_{2} \mathrm{~S} \\
3 \mathrm{HgCl}_{2(\mathrm{~g})}+2 \mathrm{H}_{2} \mathrm{~S}=\mathrm{Hg}_{3} \mathrm{~S}_{2} \mathrm{Cl}_{2(\mathrm{~s})}+4 \mathrm{HCl}
\end{gathered}
$$

From the last equation, Parks et al. ${ }^{30}$ estimated the free energy of formation of corderoite to be probably more negative that $-332.2 \mathrm{~kJ} \mathrm{~mol}^{-1}$. From this value, they calculated an Eh$\mathrm{pH}$ diagram for the $\mathrm{Hg}-\mathrm{S}-\mathrm{Cl}-\mathrm{H}_{2} \mathrm{O}$ system with $0.1 \mathrm{M}$ for the activity of chlorine. This diagram showed that corderoite requires extremely acid, mildly reducing, low $\mathrm{S}$, and high $\mathrm{Cl}$ conditions to be formed. ${ }^{30}$ Another study confirmed the estimation of $\Delta G_{\mathrm{f}}^{0}$ from Parks et al. for the formation of corderoite with a calculated value of $-396(+3,-11) \mathrm{kJ} \mathrm{mol}^{-1}$ and considered that in highly acid conditions, cinnabar reacts directly with chlorine to form corderoite: ${ }^{32}$

$$
3 \alpha-\mathrm{HgS}+2 \mathrm{H}^{+}+2 \mathrm{Cl}^{-} \leftrightarrow \mathrm{Hg}_{3} \mathrm{~S}_{2} \mathrm{Cl}_{2}+\mathrm{H}_{2} \mathrm{~S}
$$

The same equation was used by another group to explain the dissolution of cinnabar at $\mathrm{pH} 6.5$ (in the human small intestine). ${ }^{33}$

Despite these previous investigations and observations, several questions still exist on the issue of the red mercury sulfide alteration: what are the conditions inducing this phenomenon and as chlorine appears to play a role, what is the 
form of this element reacting with $\alpha-\mathrm{HgS}$, and which are the compounds formed? Different degradation compounds were already identified, and from previous observations the hypothesis was made that corderoite $\left(\alpha-\mathrm{Hg}_{3} \mathrm{~S}_{2} \mathrm{Cl}_{2}\right)$ could be an intermediate compound. ${ }^{16}$ Which role are all the degradation compounds playing?

The different reactions and diagrams presented by previous investigations ${ }^{29,30}$ did not correspond to the conditions of the present study. Thus, potential-pH diagrams were calculated to fit the conditions corresponding to the present investigation, to study the influence of these conditions on the stability of red mercury sulfide and to better understand the mechanisms involved in this alteration. Accordingly, artificial ageing experiments on model samples were performed to assess the influence of light exposure and chlorine compounds on the degradation of this pigment. With these model samples, it was important to check if the colors observed as well as the composition were similar to those of historical samples previously studied..$^{14-16}$

Indeed, as shown in Fig. 1, fragments from "The Adoration of the Magi" by Rubens ${ }^{\mathbf{1 6}}$ as well as frescoes from Villa del Torre, Pompei, ${ }^{\mathbf{1 4}}$ present a very high color variability. The initial red pigment can turn into various shades from white, grey, pink to dark purple or black as well. Concerning panel paintings, in most cases the degradation follows the shadowed areas of the painted garments and/or brushmarks. ${ }^{16}$ This distribution of the degraded areas over a painted region may indicate that a mechanical action lies at the origin of the alteration, such as the application of a product at the surface of the painting by a brush, or the heterogeneous application of the pictorial layer. Accordingly, the model samples are a good way to assess any relationship between color and chemical composition.

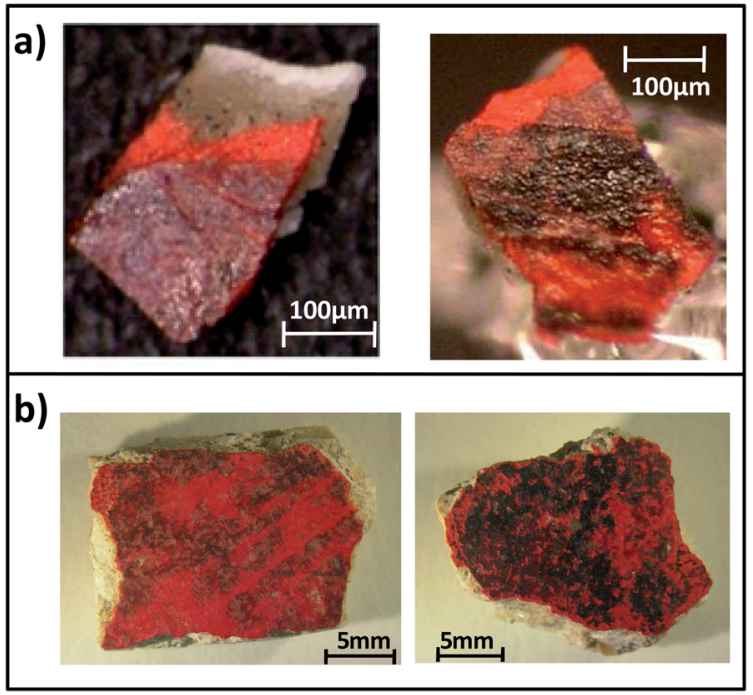

Fig. 1 Photographs of fragments taken from: (a) "The Adoration of the Magi", a painting from P. P. Rubens, Royal Museum of Fine Arts, Antwerp, Belgium; (b) a Roman fresco from Villa del Torre, near Pompeii, Italy.

\section{Materials and methods}

\subsection{Methods of thermodynamic calculation}

To obtain potential-pH diagrams of $\mathrm{Hg}-\mathrm{Cl}-\mathrm{S}-\mathrm{H}_{2} \mathrm{O}$ systems, the chemical reaction and equilibrium software HSC Chemistry ${ }^{\circledR}$ 7.0 was used with extensive thermochemical database and flowsheet simulation by Outotec Research Oy. Calculations were performed using Balej (1985) thermodynamic data, cited by Brandon et al. ${ }^{28}$ For the free energy of formation of corderoite, the lower estimation value by Paquette et $a .^{32}$ was used.

After considering the presence of the different forms of chlorine in the conditions chosen $\left(\mathrm{ClO}_{(\mathrm{g})}\right.$ being considered as the most abundant species, see 3.1.) and in order to study the evolution of the reacting system, a simulation of the reaction of $\alpha-\mathrm{HgS}$ with gaseous $\mathrm{ClO}$ (the latter added in small quantities) was performed by means of the same software. The initial composition of the system was chosen as follows to fit the conditions corresponding to the present investigation and after studying the stability of $\alpha-\mathrm{HgS}$ in the $\mathrm{Hg}-\mathrm{S}-\mathrm{Cl}-\mathrm{H}_{2} \mathrm{O}$ system (in mass percentage for the gaseous and aqueous phase):

- gaseous phase: $\mathrm{ClO}(0.01 \%)+\mathrm{CO}_{2}(0.14 \%)+\mathrm{O}_{2}(99.29 \%)+$ $\mathrm{H}_{2} \mathrm{O}(0.56 \%)$

- aqueous phase: $\mathrm{H}_{2} \mathrm{O}(92.4 \%)+\mathrm{NaOCl}(3.8 \%)+\mathrm{Na}^{+}(1.2 \%)+$ $\mathrm{ClO}^{-}(2.6 \%)$

- solid phase: $\alpha$-HgS $(0.03 \mathrm{kmol})$

Then, quantities of $\mathrm{ClO}_{(\mathrm{g})}$ added to the system were incremented by $0.2 \mathrm{~mol}$ and the composition of the system was obtained as a function of these quantities.

\subsection{Sample preparation and ageing method}

Different types of samples were prepared for artificial ageing (Table 1):

- Vermilion powder ( $\alpha$-HgS, Prolabo) without any binding medium was milled and pressed to form cylindrical pellets of 3 mm diameter and around $800 \mu \mathrm{m}$ thickness. These pellets were then partially embedded in resin in order to have at least one face not covered and to allow a direct exchange with the atmosphere. The resin employed here was a polyester resin (SODY 33) which, contrarily to the Araldite 2020, is sulfur and chlorine free.

- Next to these "pure" vermilion pellets, binary mixtures of $\alpha$ $\mathrm{HgS}$ with other compounds (1:1 mass ratio) were prepared in a similar fashion (henceforth called "mixed pellets").

- Other pellets were prepared with two layers, one layer of a powder such as $\mathrm{NaCl}$ or $\mathrm{CaCO}_{3}$ (see list of these compounds in Table 1) covered by one layer of vermilion, both pressed together to form a pellet ready to be embedded (called hereafter "two-layered pellets").

- In order to approximate more closely to the situation in actual paintings, a fourth set of samples was prepared with a binder. Linseed oil (boiled oil from Talens, reference 026) was used. Powders were ground, mixed with oil (1:3 volume ratio) and applied by brush on Melinex® (polyester) slides, as onelayer or two-layer systems. Among the one-layer systems, one was made with vermilion and lead white (Prolabo) in order to approximate the mixtures encountered in works of art. 
Table 1 Description of the compounds present in the different model samples prepared for artificial ageing experiments

\begin{tabular}{|c|c|c|c|c|c|}
\hline Types of model sample & \multicolumn{5}{|c|}{ Compounds present } \\
\hline Simple pellets & $\alpha-\mathrm{HgS}$ & & & & \\
\hline Mixed pellets & $\alpha-\mathrm{HgS}+\mathrm{NaCl}$ & & $\alpha-\mathrm{HgS}+\mathrm{CaSO}$ & & \\
\hline
\end{tabular}

These model samples (embedded pellets and painted slides) were suspended in small tubes, made in a material transparent to visible and UV light (Duran tubes, Fisher Scientific) and containing different aqueous solutions, with different halogen and sulfur species, at different $\mathrm{pH}$ (see list in Table 2). The tubes were placed in front of a fluorescent lamp (TLD 36W 965-5000 $\mathrm{K})$ that emits the solar spectrum equivalent at $4000 \mathrm{lux} \mathrm{h}$; this ensured that a complete spectrum of visible and UV wavelengths impinged on the model samples. For each condition, two tubes were prepared in parallel: one was exposed to light while the second one was wrapped in $\mathrm{Al}$ foil to keep the sample in darkness.

For all the ageing procedures, two different kinds of systems were used: a closed system and a cyclic one. The closed system consisted in a tube containing one of the solutions described above that was sealed in order to avoid exchange with ambient air. The cyclic system was manipulated in a succession of periods of $c a .80 \mathrm{~h}$ each; the tube with one of the solutions inside is sealed for $c a .80 \mathrm{~h}$ and then remains open for $c a .80 \mathrm{~h}$.

\subsection{Analytical techniques}

2.3.1. X-ray based analyses. The samples were regularly observed and analyzed by X-ray diffraction (XRD), X-ray fluorescence (XRF) and X-ray absorption near edge spectroscopy (XANES).

Micro-XRD experiments were performed with two types of instrumentation: one using a laboratory source of X-rays and another employing synchrotron radiation. The microscopic synchrotron beam size offers more possibilities of analysis, especially to characterize samples presenting micrometric alteration layers composed of heterogeneous mixtures. ${ }^{34,35}$ All samples were first analyzed in reflection mode with a laboratory
XRD instrument developed at the $\mathrm{C}^{2} \mathrm{RMF}^{36}$ based on a Rigaku MSC MicroMax 002 X-ray tube with a copper anode (wavelength of $1.5418 \AA$ ). After collimation to $200 \mu \mathrm{m}$, a monochromatic beam with a flux of $2 \times 10^{8}$ photons per s was obtained. $2 \mathrm{D}$ XRD patterns were collected by means of Rigaku $R$-axis imaging plates. FIT2D ${ }^{37}$ was used to transform the $2 \mathrm{D}$ images into standard diffractograms and the software package EVA was employed to identify the crystalline phases via comparison to a database of XRD powder patterns. Synchrotron based $\mu-X R F / \mu-$ XRD analyses were performed at ESRF beamline ID18F and at SLS beamline Micro-XAS in transmission mode. For the first instrument, a wide energy range $(6-70 \mathrm{keV})$ is accessible thanks to a Si (111) and Si (311) double crystal monochromator. The excitation energy was fixed at $28 \mathrm{keV}$ and the primary beam was focused to $5.3 \times 1.8 \mu \mathrm{m}^{2}$ (hor. $\times$ ver.) by means of a compound refractive lens. Micro-XRD patterns were collected by means of a CCD camera simultaneous to the recording of XRF spectra via an energy-dispersive $\mathrm{Si}(\mathrm{Li})$ detector. Details about the set-up can be found elsewhere. ${ }^{15,38}$ At SLS, the excitation energy was fixed at $17 \mathrm{keV}$ and the primary beam was focused to $1 \times 1 \mu \mathrm{m}^{2}$ (hor. $\times$ ver.). Micro-XRD patterns were collected by means of a Pilatus Detector. In both cases, XRD data were analyzed using the $\mathrm{XRDUA}^{39}$ software.

Synchrotron based $\mu$-XRF/ $\mu$-XANES analyses were performed at ESRF beamline ID21. ${ }^{40} \mathrm{~A}$ monochromatic primary beam is obtained thanks to a fixed-exit $\mathrm{Si}(111)$ double crystal monochromator. The accessible energy range goes from 2 to $9 \mathrm{keV}$ with a resolution of $\Delta E / E=2 \times 10^{-4}$. At the $\mathrm{S}$ and Cl K-edge energies, the beam size was reduced down to $0.60 \times 0.25 \mu \mathrm{m}^{2}$ (hor. $\times$ ver.) by means of a Fresnel zone plate. The $\mu$-XRF signal was collected in the horizontal plane by using an energydispersive Silicon Drift Diode detector. The resulting spectra

Table 2 List of the aqueous solutions used in ageing protocols with the provenance, the concentration and $\mathrm{pH}$ of each one

\begin{tabular}{|c|c|c|c|}
\hline Solution & Provenance & Concentration $\left(\mathrm{mol} \mathrm{L}^{-1}\right)$ & $\mathrm{pH}$ \\
\hline Ultra pure water $\left(\mathrm{H}_{2} \mathrm{O}\right)$ & - & - & 7 \\
\hline Sodium chloride ( $\mathrm{NaCl})$ & Prolabo & 0.505 & 9 \\
\hline Sodium hypochlorite (NaOCl) & La Croix & 15.44 & 12 \\
\hline Hydrochloric acid ( $\mathrm{HCl})$ & VWR & 32.64 & $<1$ \\
\hline Potassium chloride (KCl) & Prolabo & 0.505 & 4 \\
\hline Potassium iodide (KI) & Merck & 0.505 & 5 \\
\hline Sodium sulfate $\left(\mathrm{Na}_{2} \mathrm{SO}_{4}\right)$ & Labosi & 0.505 & 6 \\
\hline Calcium chloride dihydrate $\left(\mathrm{CaCl}_{2} \cdot 2 \mathrm{H}_{2} \mathrm{O}\right)$ & J. T. Baker & 0.505 & 4 \\
\hline Sodium hydroxide $(\mathrm{NaOH})$ & Prolabo & 16.80 & 11 \\
\hline Sulfuric acid $\left(\mathrm{H}_{2} \mathrm{SO}_{4}\right)$ & Prolabo & 18.66 & $<1$ \\
\hline
\end{tabular}


were fitted using the PyMCA software ${ }^{41}$ which is essential to differentiate the M-emission lines of mercury from the K-lines of sulfur and chlorine. Batch fitting of the XRF spectra corresponding to each pixel of the 2D maps yielded elemental maps. $\mu$-XANES spectra were recorded in XRF mode at locations determined from elemental maps. They were decomposed as a linear combination of a set of chlorine- and sulfur-reference compound spectra. From these results, it was assumed that each spectrum could be fitted as the combination of " $n$ " reference spectra. In order to obtain chemical maps showing the distribution of these different " $n$ " compounds, " $m$ " XRF maps (with $m \geq n$ ) were acquired at specific energies $E_{\mathrm{i}}$. Usually, these energies are chosen to correspond to the maximum absorption of the reference compounds and consequently the best sensitivity. At each energy $E_{\mathrm{i}}$, the intensity $I_{\mathrm{i}}$ is a linear combination of the absorption of each of the " $n$ " components. The concentrations of the components can thus be obtained by matrix inversion. At the chlorine K-edge, all mercury chlorine containing compounds show the same characteristic peak at 2.8232 $\mathrm{keV}$. The other $\mathrm{Cl}$ references studied here do not fluoresce at this energy. Consequently, XRF maps acquired at this energy show, in first approximation, the map of "mercury-chlorine" species. For normalization, a second map is usually acquired at $2.9 \mathrm{keV}$. At the sulfur K-edge, a simple ternary system (cinnabar, corderoite, calcium sulfate) was considered and three XRF maps were collected at $E_{0}=2.4716, E_{1}=2.4725$ and $E_{2}=2.4825 \mathrm{keV}$. The XRF intensities $I_{0}, I_{1}$ and $I_{2}$ can be expressed as a function of the relative concentrations of cinnabar, corderoite and sulfates and of the absorption coefficient of these three references at the three energies $E_{0}, E_{1}$ and $E_{2}$. This calculation relies on the assumption that only these three phases are present and can contribute to the XANES spectra at S K-edge.

2.3.2. Spectrocolorimetry. In order to follow the color transformations in a quantitative way, spectrocolorimetry measurements were performed at C2RMF by a NCS-RUBY confocal spectrometer (STIL) with a spot of $3 \mathrm{~mm}$ diameter. The RUBY Manager (STIL) software was used to visualize spectra and export spectral data, of which the wavelength $\lambda$ ranged from 380 to $760 \mathrm{~nm}$. The $L^{*} a^{*} b^{*}$ (CIELAB 76) color coordinate system was used with the standard illuminant D65 and $22^{\circ}$ observer. The color differences $\Delta E$ were calculated by the following equation (defined in 1976 by the Commission Internationale de l'Eclairage): ${ }^{42}$

$$
\Delta E^{*}=\left[\left(\Delta L^{*}\right)^{2}+\left(\Delta a^{*}\right)^{2}+\left(\Delta b^{*}\right)^{2}\right]^{1 / 2}
$$

2.3.3. $\mathbf{p H}$ measurements. The $\mathrm{pH}$ values of the different solutions were measured by a pH510 pH-meter (EUTECH Instruments). These values can be found in Table 2 .

2.3.4. Electron microscopy. Scanning electron microscopy/ energy dispersive X-ray (SEM/EDX) analyses were performed at C2RMF with a PHILIPS XL30CP (Controlled Pressure) instrument fitted with a tungsten filament. Observations were made under vacuum at $20 \mathrm{keV}$, with a $\mathrm{Si}-\mathrm{Li}$ detector $\left(50 \mathrm{~mm}^{2}\right.$ of active area), a Peltier cooler, and INCA software to acquire the spectral data.

\section{Thermodynamic calculations of the degradation reactions}

From previous investigations, chlorine appears to be involved in the degradation of red mercury sulfide. Samples obtained from degraded original works of art and from previously aged model samples show the presence of chlorinated compounds, more specifically $\mathrm{Hg}_{2} \mathrm{Cl}_{2}$ and polymorphous phases of $\mathrm{Hg}_{3} \mathrm{~S}_{2} \mathrm{Cl}_{2} \cdot{ }^{16}$ The understanding of the formation and the stability of these different products is an essential point of the present study. More specifically, the aim is to study the conditions inducing the degradation, such as potential, $\mathrm{pH}$ and activity of different species, and we consider it relevant to establish whether or not $\mathrm{Hg}_{2} \mathrm{Cl}_{2}$ can be formed directly from $\alpha$-HgS or whether $\alpha$ $\mathrm{Hg}_{3} \mathrm{~S}_{2} \mathrm{Cl}_{2}$ is formed as an intermediate compound of this reaction.

\subsection{Pourbaix diagrams of the $\mathrm{Hg}-\mathrm{S}-\mathrm{Cl}-\mathrm{H}_{2} \mathrm{O}$ systems}

The Pourbaix diagram for the $\mathrm{Cl}-\mathrm{H}_{2} \mathrm{O}$ system at $25{ }^{\circ} \mathrm{C}$ (Fig. 2) shows that at different $\mathrm{pH}$ and $\mathrm{Eh}$, there is an equilibrium between $\mathrm{Cl}^{-}$(aq) on the one hand and $\mathrm{ClO}^{-}$(aq) (in protonated form in neutral and acidic conditions) on the other. $\mathrm{ClO}^{-}{ }_{(\mathrm{aq})}$ or $\mathrm{HClO}_{(\mathrm{aq})}$ themselves can be further oxidized to the gaseous $\mathrm{ClO}_{(\mathrm{g})}$ in highly oxidative circumstances. At low $\mathrm{pH}(<4), \mathrm{Cl}_{2}$ is another intermediate form of chlorine in the gas phase, in redox equilibrium with $\mathrm{Cl}^{-}$and $\mathrm{HClO}$. As light also appears to be an important factor in the $\alpha-\mathrm{HgS}$ degradation phenomenon, UVactivated conditions should be studied and it would then be interesting to consider $\mathrm{ClO}_{(\mathrm{g})}$ as one of the most abundant species in the chlorinated atmosphere.

More highly oxidized forms (such as $\mathrm{ClO}_{2}{ }^{-}, \mathrm{ClO}_{3}{ }^{-}, \mathrm{ClO}_{4}{ }^{-}$) are not present in the calculated diagram, they do not appear to be stable in the chosen conditions, and only the stability domain of $\mathrm{ClO}_{(\mathrm{g})}$ is indicated.

The $\mathrm{Hg}-\mathrm{S}-\mathrm{H}_{2} \mathrm{O}$ system was studied at $25{ }^{\circ} \mathrm{C}$. When considering $\mathrm{S}$ as the predominant species (meaning that it will always be available as a reactant) (Fig. 3a), at low $\mathrm{pH}(<4)$ and high potential $(0.6<\mathrm{Eh}<0.8 \mathrm{~V})$, mercury sulfate $\left(\mathrm{Hg}_{2} \mathrm{SO}_{4}\right)$ is stable.

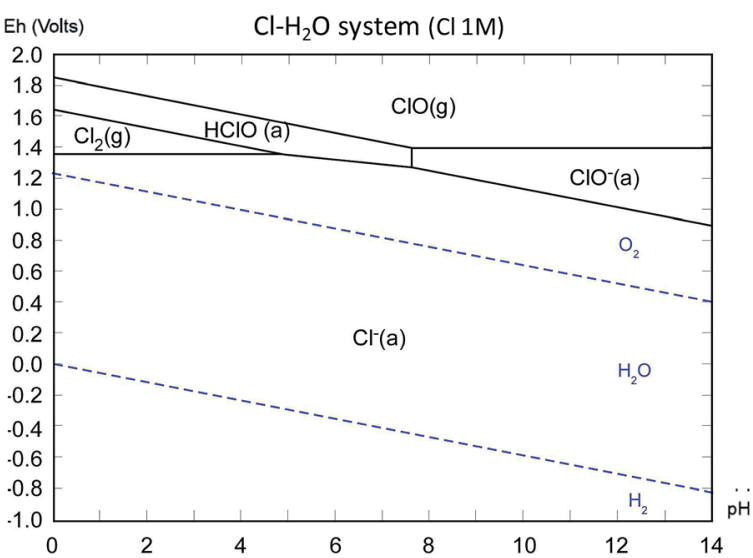

Fig. 2 Potential-pH diagram at $25{ }^{\circ} \mathrm{C}$ for $\mathrm{Cl}-\mathrm{H}_{2} \mathrm{O}$ system with in brackets activity of chlorine. 


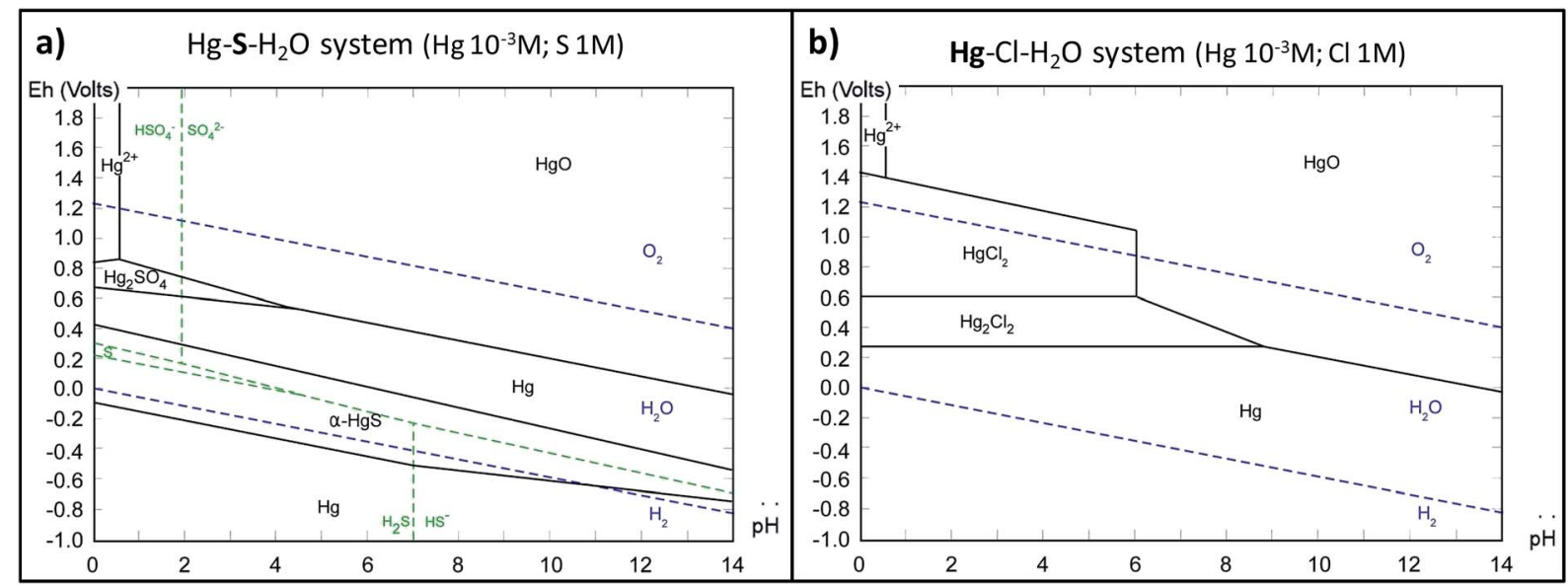

Fig. 3 Potential-pH diagrams at $25{ }^{\circ} \mathrm{C}$ for different systems with in bold the predominant species and between brackets the activities of corresponding elements.

The stability domain of $\alpha-\mathrm{HgS}$ is surrounded by the one of $\mathrm{Hg}$. Above a potential of 0 Volt, $\mathrm{HgO}$ can theoretically be formed, nevertheless this species was never identified in artificially aged or in historical samples. ${ }^{16}$ The diagram for the $\mathrm{Hg}-\mathrm{Cl}-\mathrm{H}_{2} \mathrm{O}$ system at $25^{\circ} \mathrm{C}$ with $\mathrm{Hg}$ as predominant species (Fig. 3b) shows that below pH 9, calomel $\left(\mathrm{Hg}_{2} \mathrm{Cl}_{2}\right)$ is stable (with $0.3<\mathrm{Eh}<0.6 \mathrm{~V}$ ) and in more oxidative conditions the same applies to $\mathrm{HgCl}_{2}$. Even though it was not identified during previous investigations, ${ }^{\mathbf{1 6}}$ on this diagram $\mathrm{HgCl}_{2}$ has a large stability domain at $\mathrm{pH}$ values below 6 when $0.6<\mathrm{Eh}<1.4 \mathrm{~V}$, and can be formed by the oxidation of $\mathrm{Hg}_{2} \mathrm{Cl}_{2}$.

One diagram of the $\mathrm{Hg}-\mathrm{S}-\mathrm{Cl}-\mathrm{H}_{2} \mathrm{O}$ system at $25{ }^{\circ} \mathrm{C}$ was obtained by superimposing diagrams from the $\mathrm{Hg}-\mathrm{S}-\mathrm{H}_{2} \mathrm{O}$ and $\mathrm{Hg}-\mathrm{Cl}-\mathrm{H}_{2} \mathrm{O}$ systems at the same conditions when $\mathrm{Hg}$ was the predominant species (Fig. 4a). It shows that $\mathrm{Hg}(0)$ can be stable over a large range of $\mathrm{pH}$ and at moderate Eh. It shows as well that the stability field of calomel $\mathrm{Hg}_{2} \mathrm{Cl}_{2}$ is situated in the lower $\mathrm{pH}$ range $(<9)$. Under these conditions, $\alpha-\mathrm{HgS}$ can be stable; when the electrochemical potential increases due to the increased presence of oxidizing species, $\mathrm{Hg}_{2} \mathrm{Cl}_{2}$ can be directly formed from $\alpha-\mathrm{HgS}$, without that a dominating fraction of corderoite is formed in an intermediate stage. A second diagram (Fig. 4b) of the same system at $25^{\circ} \mathrm{C}$ shows the stability domains of different mercury-containing compounds when $\mathrm{Cl}$ is the predominant element in the system (the free energy formation of $\alpha-\mathrm{Hg}_{3} \mathrm{~S}_{2} \mathrm{Cl}_{2}$ was taken from Paquette et al. ${ }^{32}$ ). In these conditions (chlorine in excess), irrespective of the redox potential or $\mathrm{pH}, \alpha-\mathrm{HgS}$ and $\mathrm{Hg}(0)$ are not stable and all dominating species contain mercury and chlorine: the stability domain of corderoite $\left(\alpha-\mathrm{Hg}_{3} \mathrm{~S}_{2} \mathrm{Cl}_{2}\right)$ ranges from $\mathrm{pH} 0$ to 14 and is relatively extended along the potential axis. Thus, contrary to what was concluded in previous studies, where it was stated that the formation of corderoite is not favorable in nature due to the necessity of an extremely acid environment, ${ }^{30}$ this diagram indicates that also at high $\mathrm{pH}$ values, corderoite can be formed. When in such conditions, the potential (Eh) increases,

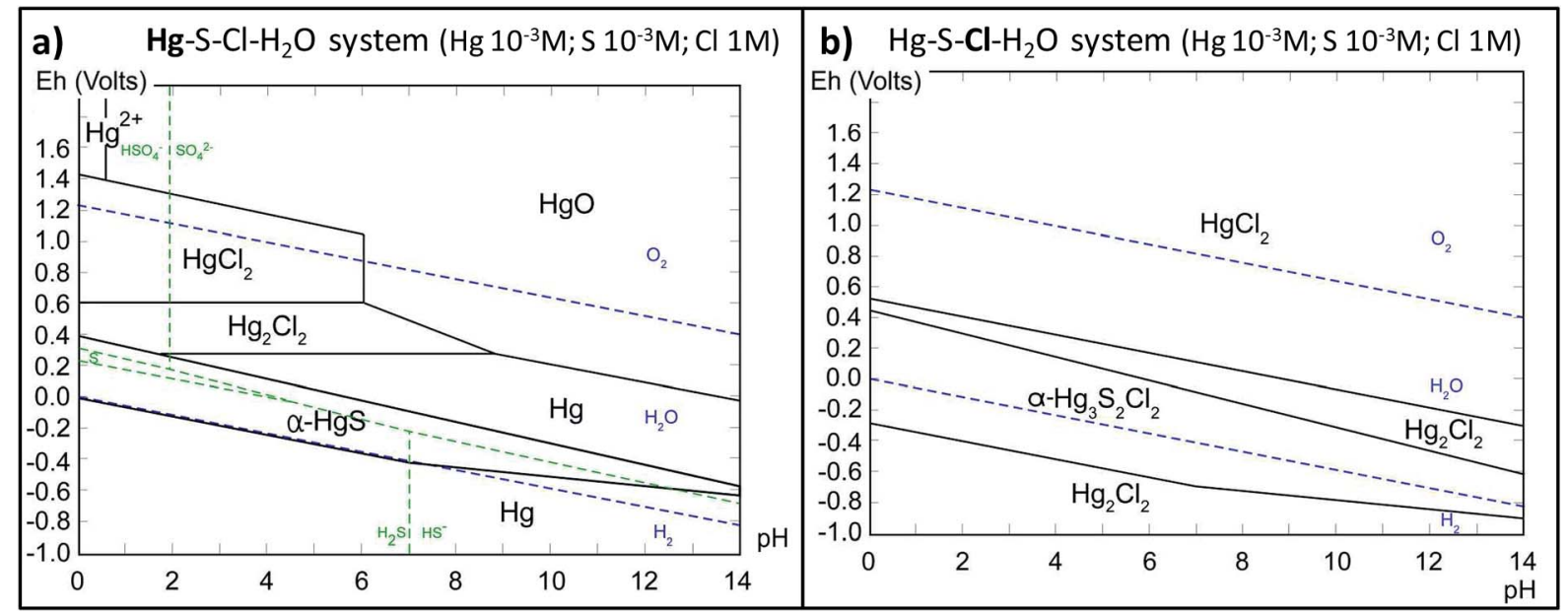

Fig. 4 Potential-pH diagrams at $25{ }^{\circ} \mathrm{C}$ for the $\mathrm{Hg}-\mathrm{Cl}-\mathrm{S}-\mathrm{H}_{2} \mathrm{O}$ system with in bold predominant species and in brackets activities of corresponding elements. 
corderoite can be converted into calomel $\left(\mathrm{Hg}_{2} \mathrm{Cl}_{2}\right)$, as observed when $\mathrm{Hg}$ is in excess (Fig. 4a). The diagram also indicates that at even higher Eh values, calomel is further oxidized to $\mathrm{HgCl}_{2}$.

From these diagrams, considering the phases that could be formed during alteration of $\alpha-\mathrm{HgS}$ and the assumption that $\mathrm{ClO}_{(\mathrm{g})}$ is one of the most abundant phases in a chlorinated atmosphere exposed to light, the following equilibria are proposed:

$$
\begin{aligned}
9 \mathrm{HgS}_{(\mathrm{s})} & +8 \mathrm{ClO}_{(\mathrm{g})}+8 \mathrm{OH}^{-} \leftrightarrows 3 \mathrm{Hg}_{3} \mathrm{~S}_{2} \mathrm{Cl}_{2(\mathrm{~s})}+2 \mathrm{Cl}^{-} \\
& +3 \mathrm{SO}_{4}{ }^{2-}+4 \mathrm{H}_{2} \mathrm{O} \\
6 \mathrm{HgS}_{(\mathrm{s})} & +14 \mathrm{ClO}_{(\mathrm{g})}+20 \mathrm{OH}^{-} \leftrightarrows 3 \mathrm{Hg}_{2} \mathrm{Cl}_{2(\mathrm{~s})}+8 \mathrm{Cl}^{-} \\
& +6 \mathrm{SO}_{4}{ }^{2-}+10 \mathrm{H}_{2} \mathrm{O}
\end{aligned}
$$

and the corresponding free energies of reaction calculated are $\Delta_{\mathrm{r}} G^{0}(1)=-838 \mathrm{kcal} \mathrm{mol}{ }^{-1}$ and $\Delta_{\mathrm{r}} G^{0}(2)=-1423 \mathrm{kcal} \mathrm{mol}^{-1}$. The negative values indicate that both reactions are thermodynamically favorable.

\subsection{Evolution of the system during the degradation process}

From previous experiments performed on degraded works of art and model samples, ${ }^{\mathbf{1 6}}$ two hypotheses could explain the simultaneous presence of both calomel and corderoite in two superimposed layers: 1: either they are formed in parallel, or 2: a sequential, multi-step process of formation takes place: $\alpha-\mathrm{HgS}$ $\leftrightarrows \alpha-\mathrm{Hg}_{3} \mathrm{~S}_{2} \mathrm{Cl}_{2} \leftrightarrows \mathrm{Hg}_{2} \mathrm{Cl}_{2}$

By means of the calculation software, a simulation of the reaction between $\alpha-\mathrm{HgS}$ and $\mathrm{ClO}_{(\mathrm{g})}$ at $25{ }^{\circ} \mathrm{C}$ was performed following the equilibria proposed (Fig. 5). In its initial state, the system only contains a limited quantity of $\alpha$-HgS (chosen to be 30 $\mathrm{mol}$ in order not to be the limiting reagent). Small quantities (0.2 mol) of $\mathrm{ClO}_{(\mathrm{g})}$ are added, and the composition of the system is followed as a function of increasing $\mathrm{ClO}_{(\mathrm{g})}$ concentration or amount added. Corderoite $\left(\alpha-\mathrm{Hg}_{3} \mathrm{~S}_{2} \mathrm{Cl}_{2}\right)$ is observed to be the first compound formed from the reaction of $\mathrm{ClO}_{(\mathrm{g})}$ with $\alpha-\mathrm{HgS}$. After the amount of $\mathrm{ClO}_{(\mathrm{g})}$ added to the $\alpha-\mathrm{HgS}$ system exceeds a threshold value, the concentration of $\alpha-\mathrm{Hg}_{3} \mathrm{~S}_{2} \mathrm{Cl}_{2}$ begins to decrease while calomel $\left(\mathrm{Hg}_{2} \mathrm{Cl}_{2}\right)$ appears. Thus, when $\mathrm{ClO}_{(\mathrm{g})}$ is added in excess

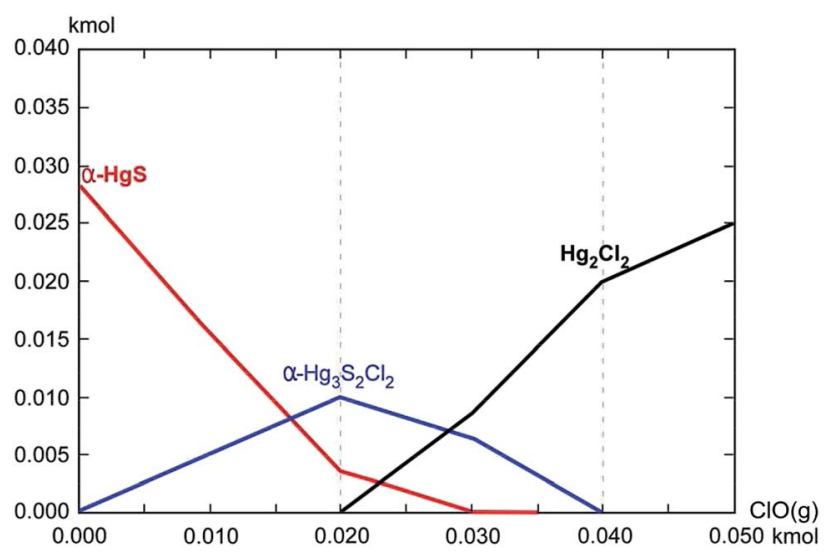

Fig. 5 Thermodynamic simulation of reactions occurring when adding $\mathrm{ClO}_{(\mathrm{g})}$ to $\alpha-\mathrm{HgS}_{(\mathrm{s})}$ at $25^{\circ} \mathrm{C}$. compared to the initial quantity of $\alpha-\mathrm{HgS}$, all of the latter compound becomes transformed in $\alpha-\mathrm{Hg}_{3} \mathrm{~S}_{2} \mathrm{Cl}_{2}$ and $\mathrm{Hg}_{2} \mathrm{Cl}_{2}$, the first one being in lower proportion. For even higher $\mathrm{ClO}_{(\mathrm{g})}$ concentrations, the equilibrium completely shifts towards $\mathrm{Hg}_{2} \mathrm{Cl}_{2}$.

\section{Results of artificial ageing experiments}

The thermodynamic calculations performed showed that the reaction of $\alpha-\mathrm{HgS}$ with chlorine, and more specifically $\mathrm{ClO}_{(\mathrm{g})}$, induces the formation of different chlorine-containing compounds. In order to reproduce experimentally this degradation, artificial ageing experiments were performed with different solutions.

During all the artificial ageing experiments, the first noteworthy result concerns the influence of light. Indeed, when samples were kept in darkness, irrespective of the type of sample or the environment present, no visual change was noticed, after a maximum of 218 days; samples remained red, and nothing else than $\alpha-\mathrm{HgS}$ was detected by SEM, XRD, XRF or XANES. Therefore, in the conditions evaluated, we can conclude that light is mandatory for the degradation of $\alpha$-HgS. Accordingly, in what follows, only the results of artificial ageing treatments involving exposure to light will be presented.

An overview of the relevant ageing results is presented in Fig. 6. The ageing of vermilion samples with solutions not containing chlorine (cited above in 2.2.) did not give rise to any visual change at sample surface while no other compounds than mercury sulfide were identified by elemental and structural analyses, even after 260 days of exposure. Concerning the chlorine containing solutions, experiments over the same length of time with $\mathrm{CaCl}_{2} \cdot 2 \mathrm{H}_{2} \mathrm{O}, \mathrm{HCl}$ and $\mathrm{KCl}$ solutions also did not yield any significant modification in the visual aspect or of the chemical composition of the model samples.

The exposure to light and to a solution of $\mathrm{NaOCl}$ (see par. 4.1.) of the "pure" vermilion and the two-layered and mixed model samples prepared with different compounds

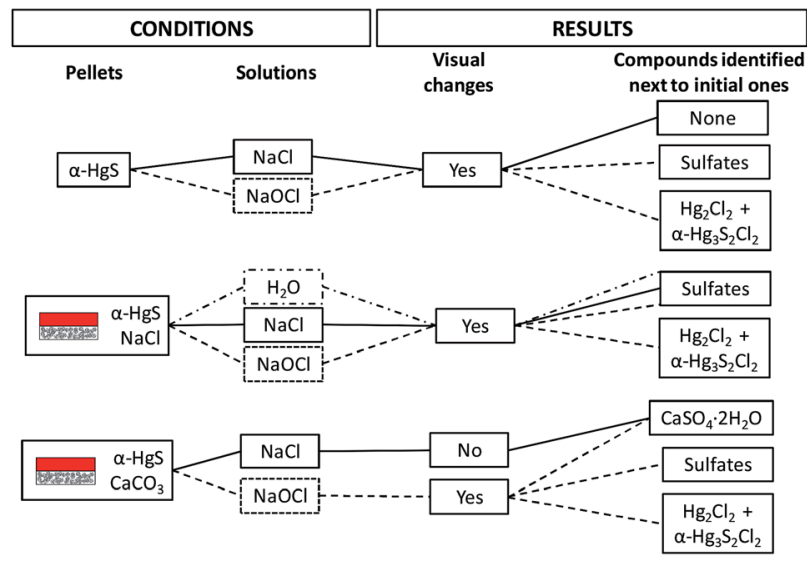

Fig. 6 Summary of some of the ageing experiments performed on pellets (without any binder) in front of light and showing modifications in the visual aspect of the pellets or/and appearance of new compounds at the surface identified by XRD or $\mu$-XANES. 
$\left(\mathrm{CaSO}_{4} \cdot 2 \mathrm{H}_{2} \mathrm{O}, \mathrm{KCl}, \mathrm{Na}_{2} \mathrm{SO}_{4}\right.$, lead white) yielded comparable results, i.e. a color change was observed and sulfates and mercury chloride compounds could be identified. Also the twolayered pellets prepared with $\mathrm{NaCl}$ and vermilion (see par. 4.2.) and the ones with calcite and vermilion (see par. 4.3.) yielded relevant results.

After several contact periods with the ambient air, the $\mathrm{pH}$ of the $\mathrm{NaOCl}$ solutions invariably changed from 12.2 to 9.4 , giving rise to the formation of a white precipitate at the bottom of the tube, identified by XRD to consist of halite $(\mathrm{NaCl})$ and sodium chlorate $\left(\mathrm{NaClO}_{3}\right)$. When $\mathrm{Na}$ is present in the ageing solution, it is never detected at the surface of the sample, except, obviously, when $\mathrm{Na}$ is originally present in the model sample. This observation supports the hypothesis that $\mathrm{Cl}$ is transferred through a gaseous form and not through an aqueous phase that would contain both $\mathrm{Na}^{+}$and $\mathrm{Cl}^{-}$ions.

\subsection{Artificial ageing with $\mathrm{NaOCl}$ solution and light}

During artificial ageing experiments, a sodium hypochlorite solution $(\mathrm{NaOCl})$ was used to produce highly oxidative chloride compounds such as $\mathrm{ClO}_{(\mathrm{g})}$, in order to reproduce the mechanisms studied by thermodynamic calculations. All experiments described below were performed multiple times (two or more depending on the results obtained) in order to ensure the reproducibility of the results. Irrespective of the composition of the sample (vermilion powder, mixed pellets, two-layered pellets, with or without any binder), in all cases superficial color changes were observed, but not exactly the same in all circumstances (see Fig. 7). However, always the same chlorinecontaining compounds were identified by XRD: calomel $\left(\mathrm{Hg}_{2} \mathrm{Cl}_{2}\right)$ and corderoite $\left(\alpha-\mathrm{Hg}_{3} \mathrm{~S}_{2} \mathrm{Cl}_{2}\right)$. These compounds are also encountered on degraded works of art (and on artificially aged samples we described preliminary ${ }^{\mathbf{1 6}}$ ) and suggest a good agreement between natural and artificial ageing. Moreover, from thermodynamic calculations, it was seen that from the reaction of $\mathrm{ClO}_{(\mathrm{g})}$ (from $\mathrm{NaOCl}$ solution) with $\alpha-\mathrm{HgS}$, calomel and corderoite can be formed (see par. 3.).

As can be seen in Fig. 7, initially (after 5-10 days), the samples acquire a purple color due to the presence of a thin light-grey layer of degraded material at the surface (Fig. 7a), sometimes accompanied by the formation of white crystals (square, translucent, hundreds of micrometers large, tens of micrometers thick) (Fig. 7a-c). Between identically treated pellets (not shown in Fig. 7), large differences in the visual aspect may occur. In Fig. 7a, after 8 days, a thin light-grey veil is visible on the surface of the pellet that is thicker in some areas. In Fig. $7 b$, after 20 days the surface becomes covered by dark grey areas, a color that was seen only on few pellets. The pellet in Fig. 7c has a very homogeneous and smooth surface prior to ageing, and with all the pellets of this surface finish, the formation of large crystals was observed after 7 days of ageing. After $c a .30$ days these crystals and the entire surface become covered with a thick white/light-grey layer. This white/grey color is not exactly the same for each pellet aged in these conditions, perhaps due to a variation in thickness of the degradation layer, or due to variations in the morphology of the crystals formed during this degradation. Table 3 lists the $\Delta E^{*}$ values obtained by means of spectro-colorimetry from different pellets. On $\alpha$ $\mathrm{HgS}$ pellets aged in the same conditions ( $\mathrm{NaOCl}$ solution, light, closed system) two different steps with important $\Delta E^{*}$ values appeared during ageing: one at the formation of crystals, and the second at the formation of the thick white layer.

The degraded model samples show different kind of crystals at the surface: these may be small, white and homogeneously distributed over the surface, giving it a purple color (Fig. 7a) or they may be large, squarish, translucent and localized heterogeneously, so that the original red color of the vermilion remains visible (Fig. 7c). After some time, a thick and homogeneous layer may appear, giving the surface a white to lightgrey color (Fig. 7). In its natural form, calomel $\left(\mathrm{Hg}_{2} \mathrm{Cl}_{2}\right)$ is a rare

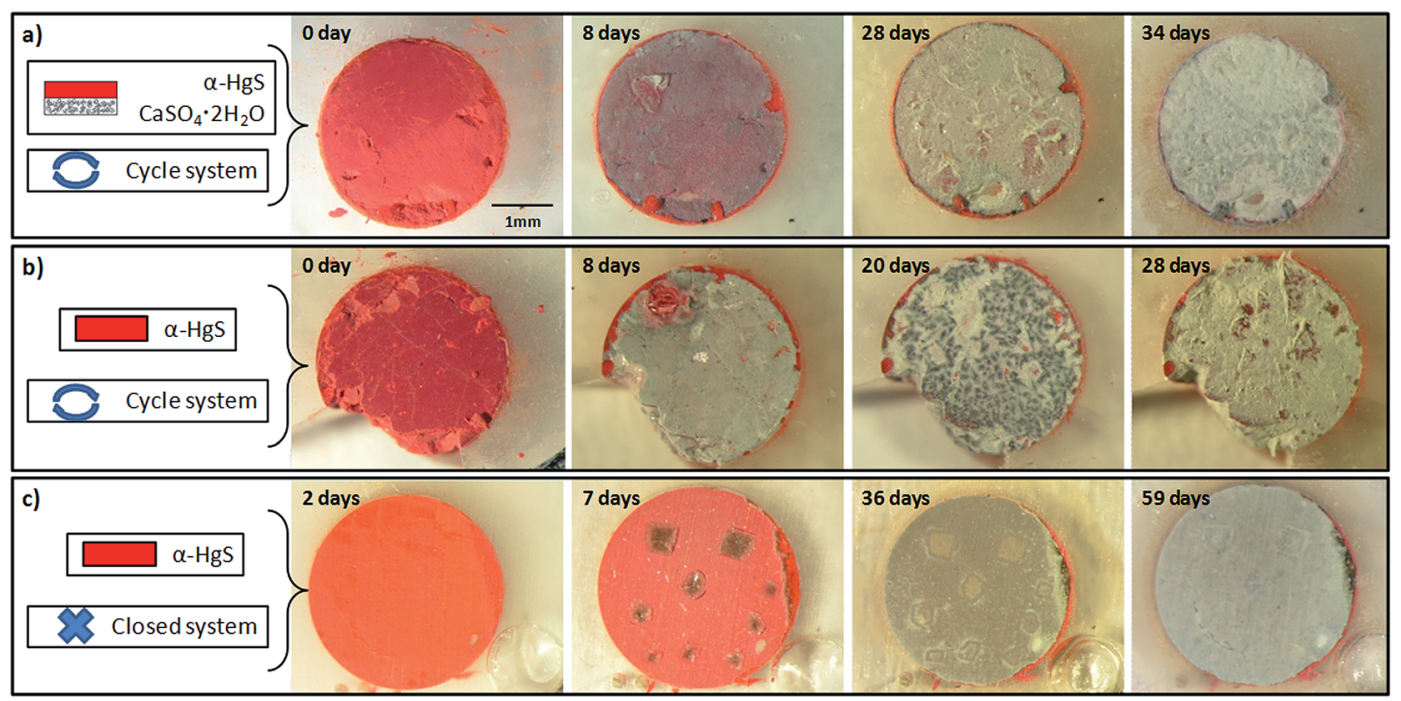

Fig. 7 Pellets aged with $\mathrm{NaOCl}$ solution and light at different times of ageing: (a) two-layered pellet of gypsum/vermilion in cycle system; (b) pellet of vermilion in cycle system; (c) pellet of vermilion in closed system. 
Table 3 Color coordinates $L^{*}, a^{*}$ and $b^{*}$ and resulting color differences (expressed as $\Delta E^{*}$ ) induced by a specific period of exposure to NaOCl or $\mathrm{NaCl}$ solutions and light, in closed systems. Evolution of color or differences between pellets $\left(\Delta E^{*}\right)$ is calculated via the CIE formula. A change of color is perceptible to the eye from 1-1.5

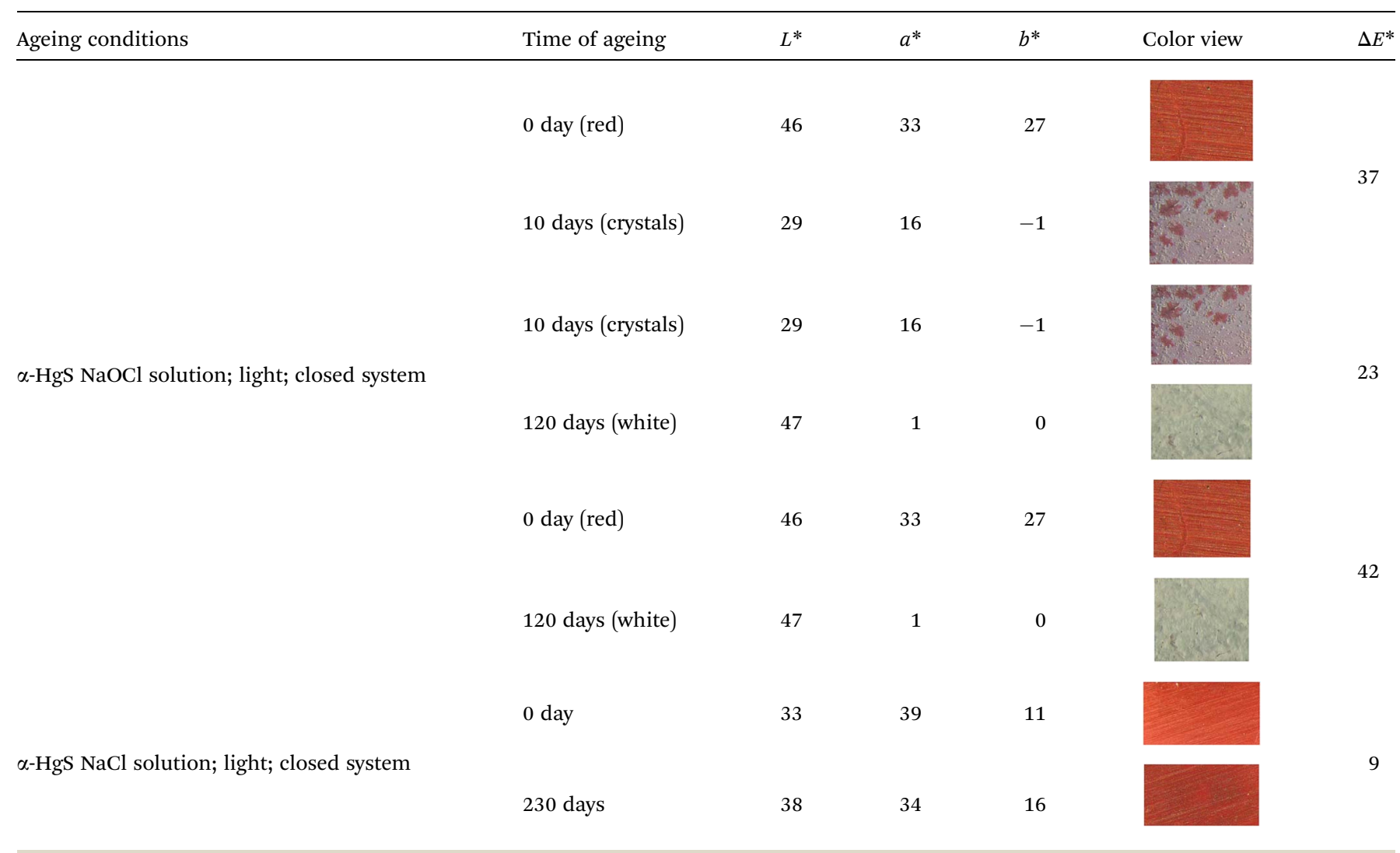

white ore, essentially found in association with cinnabar. Corderoite $\left(\alpha-\mathrm{Hg}_{3} \mathrm{~S}_{2} \mathrm{Cl}_{2}\right)$, as well as the related compounds kenhsuite $\left(\gamma-\mathrm{Hg}_{3} \mathrm{~S}_{2} \mathrm{Cl}_{2}\right)$ and $\beta-\mathrm{Hg}_{3} \mathrm{~S}_{2} \mathrm{Cl}_{2}$, have already been found on degraded works of art. ${ }^{16,18}$ Corderoite is a light orange-pink mineral known as turning grayish-black when exposed to light. ${ }^{43}$ Kenhsuite, naturally associated with cinnabar and corderoite and more recently found in a Nevada deposit (McDermitt), is a yellow ore also observed as being photosensitive. ${ }^{44}$ Calomel $\left(\mathrm{Hg}_{2} \mathrm{Cl}_{2}\right)$ is usually white in nature. Accordingly, the color of these phases is in good agreement with the white, pink or purple shades observed on some paintings and on the aged pellets. However, the dark/black color of the alteration found on some works of art $^{14}$ as well as on some pellets (Fig. 7b, 20 days) cannot be explained by the natural color of any of these phases. Accordingly, it appears that the black color is due to one or several unidentified species (see discussion below).

SEM/EDX analyses were performed at the surface of different pellets to localize the degradation compounds identified by XRD and study in greater detail their contribution to the visual changes. Four locations of a two-layered pellet $(\mathrm{NaCl} / \alpha-\mathrm{HgS})$ aged during 90 days in a closed system (Fig. 8a) were analyzed; the resulting BSE image (Fig. 8b) shows the presence of small squarish, translucent crystals at the surface corresponding to halite (Fig. 8c, point 3), surrounded by fine crystallizations with a higher BSE intensity. In point $4, \mathrm{Hg}$ and $\mathrm{Cl}$ are present in approximately equal atomic abundance (Fig. 8c). While the origin of the halite is clearly the sub-layer of the pellet, calomel $\left(\mathrm{Hg}_{2} \mathrm{Cl}_{2}\right)$ is a degradation product whose presence on this pellet was confirmed by XRD.

Paint fragments from original works of art featuring degraded $\alpha-\mathrm{HgS}$ usually present a complex multilayered stratigraphy. ${ }^{16}$ In previous research we observed the formation of a succession of layers comprising $\alpha-\mathrm{HgS}$ (lower layer), $\mathrm{Hg}_{3} \mathrm{~S}_{2} \mathrm{Cl}_{2}$ (intermediate layer) and $\mathrm{Hg}_{2} \mathrm{Cl}_{2}$ (top most layer), further covered by sulfates such as gypsum $\left(\mathrm{CaSO}_{4} \cdot 2 \mathrm{H}_{2} \mathrm{O}\right)$, suggestive of a multi-step alteration mechanism. With the aim of observing similar structures in the model samples (if any), some of the artificially aged samples were prepared as cross-sections by embedding them in SODY 33 resin. All the cross-sections present a degradation layer 10-50 $\mu \mathrm{m}$ in thickness on top of the $\alpha-\mathrm{HgS}$ layer. This layer appears white or light grey under visible light. These cross-sections were analyzed by SEM (C2RMF, Paris, France), $\mu$-XRD at beamline ID18F and by $\mu$-XRF/ $\mu$-XANES at beamline ID21 of ESRF (Grenoble, France). When calomel and corderoite were detected by XRD on the surface of a sample, its cross-section showed that, within the achievable resolution $(c a .2 \mu \mathrm{m})$, these two compounds are co-localized in the same layer covering the vermilion (see Fig. 9c). XANES and chemical mapping at ID21 was used to confirm the distribution of the 


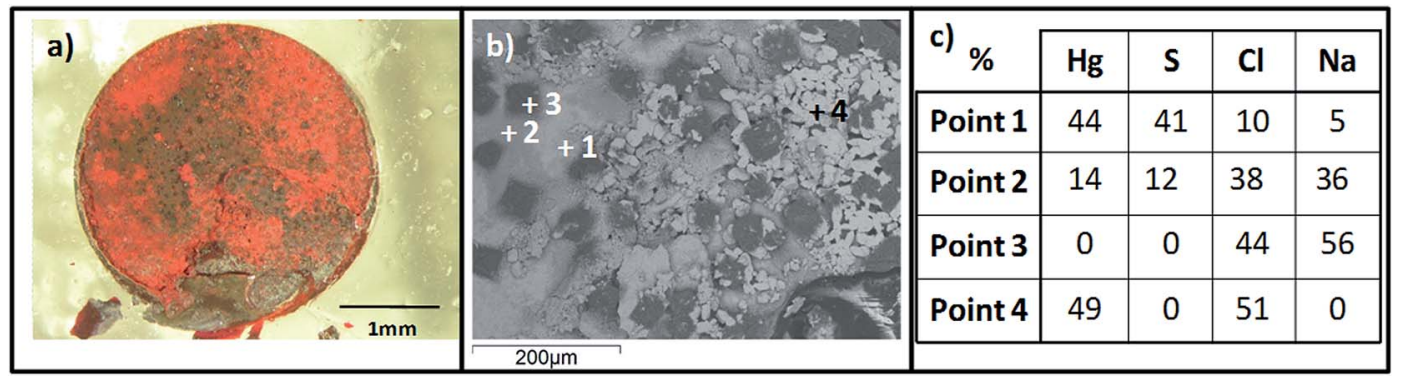

Fig. 8 Two-layered $\mathrm{NaCl} /$ vermilion pellet aged with $\mathrm{NaOCl}$ solution and light in a closed system: (a) visible image of the pellet; (b) BSE image of a part of the surface, obtained by SEM; (c) results of quantitative SEM analyses performed on the four points shown in (b) (in atomic percentage; Hg, $\mathrm{S}, \mathrm{Cl}$ and $\mathrm{Na}$ concentrations were normalized to a total of $100 \% ; \mathrm{C}, \mathrm{O}$ and $\mathrm{Al}$ datas not shown here).

compounds with a better resolution $(0.25 \mu \mathrm{m}$ vertical $)$. Above the vermilion layer, spectra obtained by XANES analyses showed a peak at $2.8232 \mathrm{keV}$, the energy of Cl K-edge maximum absorption of mercury chlorine containing compounds. On some of the samples, a thick layer was present on top of the cross-sections, and in this layer XANES analyses showed spectra with a peak at $2.4828 \mathrm{keV}$, the energy of $\mathrm{S}$ K-edge maximum absorption corresponding to the presence of sulfates. Moreover, for some samples, on these spectra it was possible to identify features similar to the XANES reference spectrum of gypsum, as previously observed on some original works of art (see Fig. 9a and b). Gypsum can be transparent, white or light yellow in color.
In the majority of the cases ( 9 out of 14), and after a minimum of 40 hours exposed to $\mathrm{NaOCl}$ solution and light, the degradation products calomel and corderoite were found to be formed simultaneously. However, in some cases (5 out of 14), after a specific ageing time, only one of them, either calomel or corderoite, remained (see Table 4 for a summary). It is noteworthy among these five cases, only on the pellets aged in a closed system ( 2 cases) corderoite remained as final product, while those aged in the cyclic system (3 cases) showed calomel to be the final product. The latter three cases developed a thick white/light-grey superficial layer while the former two acquired a purplish hue. During ageing experiments, when the vessel is opened, the activity of $\mathrm{O}_{2(\mathrm{~g})}$ increases, causing an increase in Eh

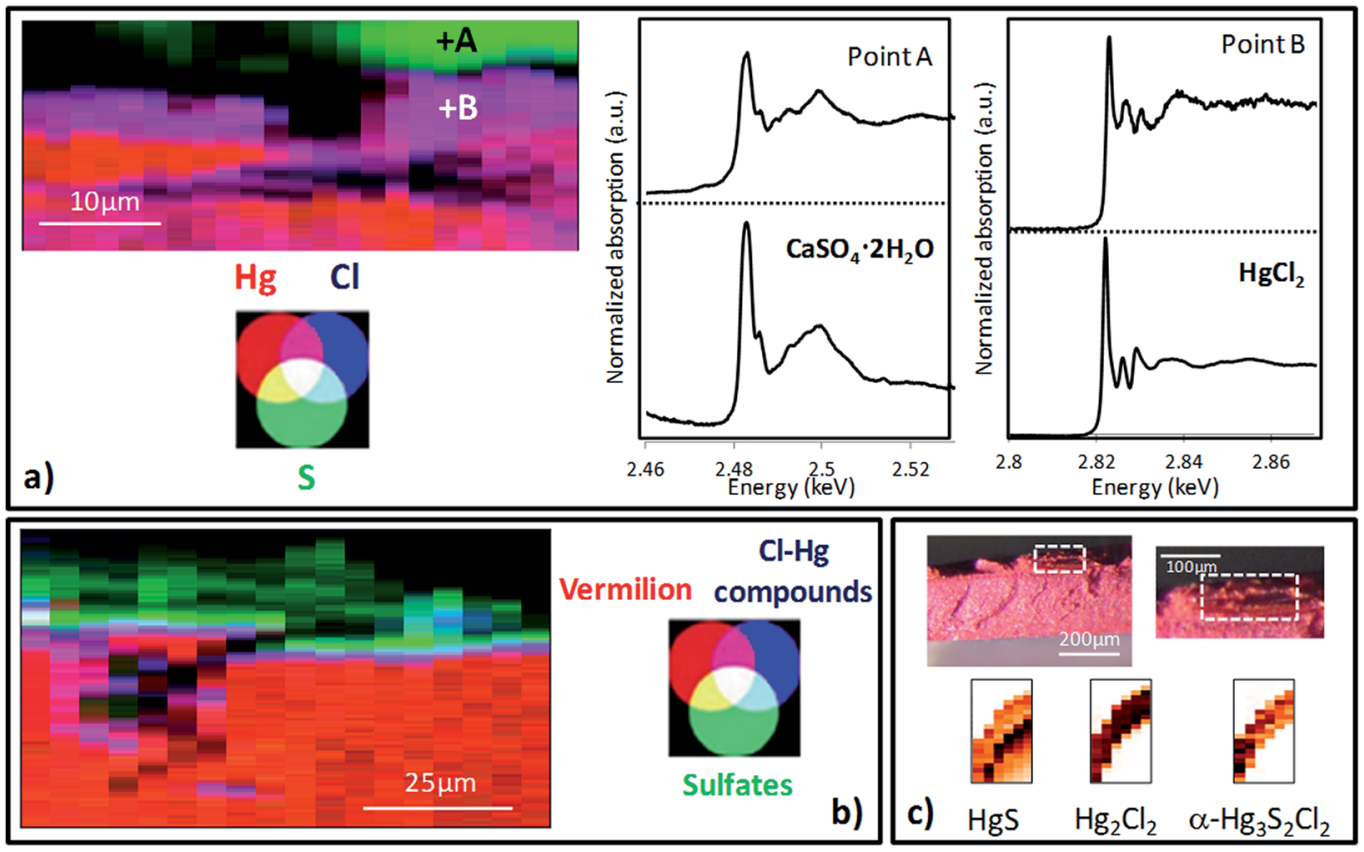

Fig. 9 Images and spectra of 3 cross-sections of different pellets aged with a $\mathrm{NaOCl}$ solution and light in a closed system: (a) elemental maps obtained by $\mu$-XRF at $2.9 \mathrm{keV}$ on a two-layered calcite/HgS pellet showing in purple a layer containing $\mathrm{Hg}$ and $\mathrm{Cl}$ and in green a layer with sulfur on top of the sample (sulfates), both presences being confirmed by XANES spectra performed on the points A ( $\mathrm{K}$-edge) and B (Cl K-edge) compared to corresponding references; (b) chemical maps obtained by combined $\mu$-XRF/ $\mu$-XANES on a two-layered NaCl/HgS pellet showing an intermediate layer of $\mathrm{Cl}-\mathrm{Hg}$ compound; (c) phase maps obtained by $\mu$-XRD performed on the dashed rectangle represented on the visible picture of the $\mathrm{HgS}$ pellet, showing the co-localization of the two degradation compounds (the distortion of the maps is due to technical problems during the experiment). 
Table 4 List of the pellets exposed to $\mathrm{NaOCl}$ solution and light in which calomel $\left(\mathrm{Hg}_{2} \mathrm{Cl}_{2}\right)$ and corderoite $\left(\alpha-\mathrm{Hg}_{3} \mathrm{~S}_{2} \mathrm{Cl}_{2}\right)$ were initially formed simultaneously but where XRD showed only one of these two remaining as final degradation product

\begin{tabular}{|c|c|c|c|}
\hline Pellet composition & $\begin{array}{l}\text { Type of ageing } \\
\text { system }\end{array}$ & $\begin{array}{l}\text { Total time } \\
\text { of ageing }\end{array}$ & $\begin{array}{l}\text { Compound remaining } \\
\text { (as identified by XRD) }\end{array}$ \\
\hline Two-layered $\{\mathrm{NaCl} /$ vermilion $\}$ & Closed & 130 days & Corderoite \\
\hline Two-layered $\{\mathrm{KCl} /$ vermilion $\}$ & Closed & 95 days & Corderoite \\
\hline Vermilion & Cycle & 85 days & Calomel \\
\hline Two-layered $\{\mathrm{NaCl} /$ vermilion $\}$ & Cycle & 104 days & Calomel \\
\hline Two-layered \{gypsum/vermilion\} & Cycle & 58 days & Calomel \\
\hline
\end{tabular}

so that, following the Pourbaix diagram of the $\mathrm{Hg}-\mathrm{S}-\mathrm{Cl}-\mathrm{H}_{2} \mathrm{O}$ system with chlorine as the predominant element (see Fig. 4b), the redox equilibrium between corderoite and calomel shifts towards the latter compound. This explains the predominance of calomel in the samples aged using the cyclic system. The diagram also indicates that at even higher Eh values, calomel is further oxidized to $\mathrm{HgCl}_{2}$, but this compound was not observed experimentally.

\subsection{Influence of $\mathrm{NaCl}$ on ageing results}

Next to the experiments performed with NaOCl solutions, other ageing conditions giving rise to either visual or chemical changes on the model samples were studied. As previously described, ${ }^{\mathbf{1 6}}$ ageing with a $\mathrm{NaCl}$ solution appeared to take much longer and gave rise to less important color changes in a few cases. Indeed, as presented in Table 3 , for $\alpha$-HgS pellets exposed to $\mathrm{NaCl}$ solutions and light in a closed system during 230 days, the obtained $\Delta E^{*}$ value was $c a$. 9 , which is significantly smaller than the differences obtained for the pellets aged in $\mathrm{NaOCl}$ solutions (see Table 3). Nevertheless, changes of color are perceptible to the eye starting from $\Delta E^{*}$ values of $1-1.5$. The representation of these results in the CIE $a^{*} b^{*}$ space compared to those corresponding to $\mathrm{NaOCl}$ solution ageing (see Fig. 10) shows that for $\mathrm{NaCl}$ solution ageing, even after 230 days, the difference from the unaged pellet is far smaller than for $\mathrm{NaOCl}$ solution ageing after 120 days. The $L^{*} a^{*} b^{*}$ differences between the two unaged pellets are attributed to sample preparation variations; even with the same $\alpha$-HgS quantity introduced in the press, it is difficult to apply pressure in a reproducible manner on the powders. Thus, pellets did not all show the same red shade prior to ageing.

When $\mathrm{NaCl}$ was originally present in the model samples (mixed pellets), Na was detected by SEM/EDX analyses at the degraded surface. On the other hand, whatever the ageing conditions, Na was never detected by SEM at the surface of the other samples. In the cases where ageing was performed in the presence of a $\mathrm{NaCl}$ solution, it also was not possible to detect any chlorine-containing compound at the surface of aged pellets by any elemental or structural analysis method.

In order to further investigate the direct influence of sodium chloride solutions on vermilion, the following three experiments were done. First, droplets of $\mathrm{NaCl}$ solution were directly applied on the surface of an $\alpha$-HgS pellet and this was exposed to light in a closed system. In this case, after ageing, no other phases than $\mathrm{HgS}$ and halite $(\mathrm{NaCl})$ crystals were detected at the surface of this sample. Secondly, $\mathrm{NaCl}$ crystals were mixed with linseed oil and applied as a varnish layer on top of a paint layer of vermilion, itself painted on a glass slide. After 129 days of exposure to light in a closed system, dark brown stains were visible on the paint slide. However, visual inspection of the sample slide showed that the vermilion layer was still red, suggesting that the dark aspect of the sample was attributed to the dissolution of some of the halite crystals in oil, hereby changing the refraction index of the binder and causing it to look darker. Next to vermilion and halite $(\mathrm{NaCl})$, in S K-edge $\mu$ XANES spectra, peaks corresponding to the energies of maximum absorption for corderoite $\left(\alpha-\mathrm{Hg}_{3} \mathrm{~S}_{2} \mathrm{Cl}_{2}\right)$ and sulfates were observed. In the spectrum obtained, next to the peak assumed to correspond to sulfates (at $2.4826 \mathrm{keV}$ ), a shoulder at a lower energy was visible. These features are somewhat similar to the S K-edge spectrum of $\mathrm{HgSO}_{4}$. However this compound was not detected by any other analytical technique such as XRD.

The ageing experiments involving $\mathrm{NaCl}$ that yielded important visual differences were observed on two-layered pellets with abundant $\mathrm{NaCl}$ in the lower layer. Irrespective of the ageing solution (without or with water, $\mathrm{NaCl}$ or $\mathrm{NaOCl}$ solutions, in closed or cycle systems), all two-layered $\mathrm{NaCl} / \alpha-\mathrm{HgS}$ pellets exposed to light developed dark areas at the surface. The pellets aged in a closed system only showed some grey spots (Fig. 11d) whereas the ones aged in a cyclic system became dark grey (Fig. 11a-c). In those areas of the samples that were covered by the embedding resin, a darker color was observed, approaching

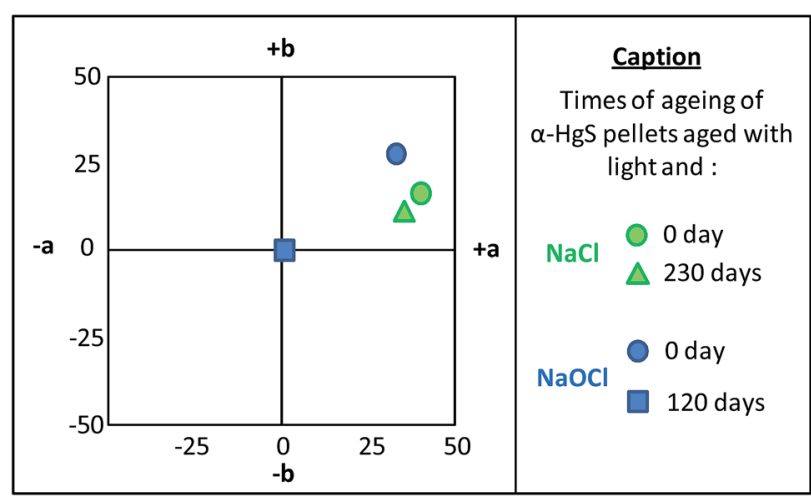

Fig. 10 Color measurements cited in Table 1 and represented in the $\mathrm{CIE} a * b *$ space for $\alpha-\mathrm{HgS}$ pellets aged with $\mathrm{NaCl}$ and $\mathrm{NaOCl}$ solutions in closed systems. 


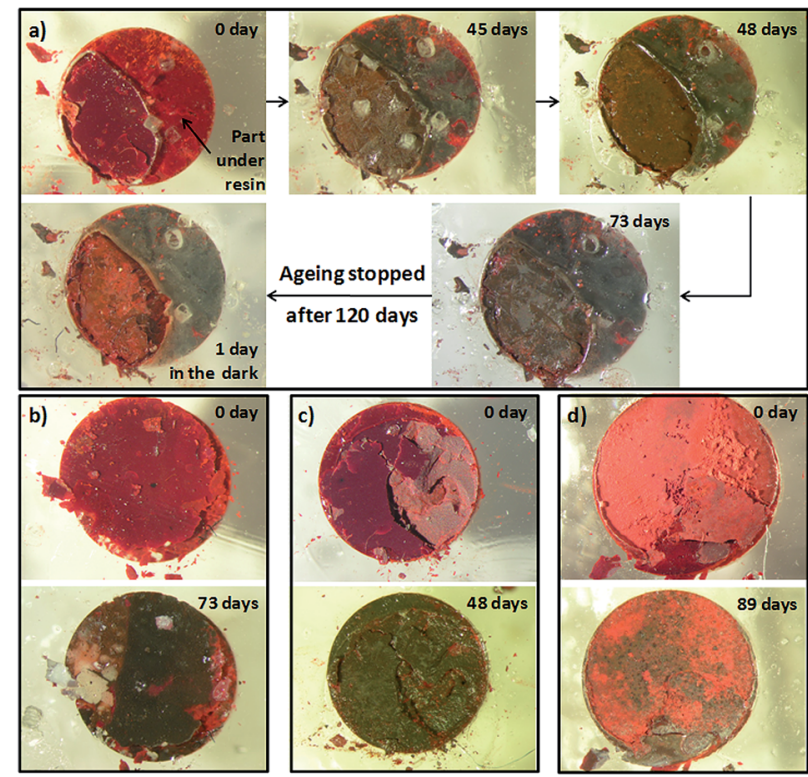

Fig. 11 Two-layered pellets of $\mathrm{NaCl} /$ vermilion powders aged under different conditions: (a) in $\mathrm{NaCl}$ solution (cycle system); (b) in $\mathrm{NaOCl}$ solution (cycle system); (c) in $\mathrm{H}_{2} \mathrm{O}$ solution (cycle system); (d) in $\mathrm{NaOCl}$ solution (closed system).

black (Fig. 11a). Even in the case of ageing with a NaOCl solution, when other compounds such as calomel and corderoite were formed, the surface sample still looked dark grey (Fig. 11b), i.e. much darker than in the cases no $\mathrm{NaCl}$ substrate layer was present. However, for all these cases, no other compounds than $\alpha$-HgS (plus calomel and corderoite for pellets aged by $\mathrm{NaOCl}$ solution) could be identified by XRD; in S K-edge XANES spectra, a peak corresponding to sulfates (at $2.4825 \mathrm{keV}$ ) was present. It is also noteworthy that after the ageing was stopped, after some time in darkness, these dark grey pellets became red again, except for the parts situated below the resin (see Fig. 11a).

\subsection{Formation of sulfates on pellets}

As already seen in Fig. 9, a characteristic peak for sulfates at $2.4825 \mathrm{keV}$ appeared in the S K-edge XANES spectra, which does not match any of the investigated sulfate references (see gypsum reference in Fig. 9a). This unknown type of sulfate was observed in all pellets aged with $\mathrm{NaOCl}$ solution and also in all two-layered pellets composed of $\mathrm{NaCl} / \alpha-\mathrm{HgS}$ that were aged with $\mathrm{H}_{2} \mathrm{O}$ and $\mathrm{NaCl}$ solutions in closed or cycle system. These sulfates were found also out of the pellets, at the surface of the resin embedding the pellets. By analyzing the surface layer of a two-layered pellet composed of $\mathrm{CaSO}_{4} \cdot 2 \mathrm{H}_{2} \mathrm{O} / \alpha-\mathrm{HgS}$ aged with $\mathrm{NaOCl}$ solution in closed system by $\mu$-XRD at the SLS facility, another sulfate compound, not originally present in the model sample before the ageing experiment, was identified: $\mathrm{Hg}_{2} \mathrm{SO}_{4}$. This phase was only identified once (in a series of over 50 aged pellets) and was not detected on original degraded works of art. $^{16}$
Some two-layered vermilion pellets were prepared having a calcite $\mathrm{CaCO}_{3}$ substrate layer in order to simulate more closely the situation encountered in original works of art, where the pictorial layers are frequently applied on top of a chalk-glue ground layer. After exposure to light and air or water, these samples remained unaltered (no visual changes, no difference detected by structural analyses). After exposure to light in a closed tube containing a $\mathrm{NaCl}$ solution, only one pellet showed a very slight visual change (some areas presented a purple aspect). After 182 days of ageing, gypsum $\left(\mathrm{CaSO}_{4} \cdot 2 \mathrm{H}_{2} \mathrm{O}\right)$ was detected on its surface by XRD. However, this result could not be reproduced. After 28 days of exposure to light in a closed tube containing $\mathrm{NaOCl}$ solution, the powder without any binder (two-layered pellet) presented a light grey color and next to calomel and corderoite, gypsum was identified on its surface by XRD and XANES ( $c f$. the S K-edge spectrum on point A Fig. 9a compared to the one of gypsum). When the powder was mixed with linseed oil (two-layered painted slide), gypsum was detected after 170 days of ageing and the red color of the surface completely turned brown-dark grey. For these experiments with $\mathrm{NaOCl}$ solution in closed systems, the results were reproducible. These results are in good agreement with observations made on Pompeian degraded red paintings. ${ }^{14}$ In this previous study, two sources of sulfates were proposed: an environmental contamination by $\mathrm{SO}_{2}$, as it was determined to be responsible for the blackening of hematite and for the presence of gypsum on altered wall paintings, ${ }^{45}$ or the oxidation of sulfide present in the red pigment. These experiments show that, even if the first hypothesis is as well rather plausible in real conditions, part of the sulfates can originate from the sulfide pigment. Eqn (1) and (2) also support the fact that sulfates are formed as by-products of the reaction of $\mathrm{ClO}$ with $\alpha$-HgS. In the presence of a calcium source (here and at Pompeii as calcite), the precipitation of calcium sulfates makes these reactions more favorable.

\section{Conclusions}

The objectives of the present study were to assess the influence of light exposure and chlorine compounds on the alteration of red mercury sulfide and to better understand the mechanisms involved in the formation and evolution of the degradation compounds.

In order to have a better insight into the factors that influence the alteration and into the reactions that may occur during the degradation of $\alpha-\mathrm{HgS}$, thermodynamic calculations and experiments involving artificial ageing of $\alpha$-HgS model samples were performed. From the study of the $\mathrm{Hg}-\mathrm{S}-\mathrm{Cl}-\mathrm{H}_{2} \mathrm{O}$ system, it can be concluded that calomel $\left(\mathrm{Hg}_{2} \mathrm{Cl}_{2}\right)$, corderoite $\left(\alpha-\mathrm{Hg}_{3} \mathrm{~S}_{2} \mathrm{Cl}_{2}\right)$ and sulfates can be formed from the reaction of $\alpha-\mathrm{HgS}$ with $\mathrm{ClO}_{(\mathrm{g})}$. These degradation products were indeed identified after artificial ageing experiments of red mercury sulfide by exposure to light and $\mathrm{NaOCl}$ solution. These experiments also showed that light is a necessary factor to obtain degradation. According to Pourbaix diagrams, both calomel and corderoite can be formed at basic $\mathrm{pH}$, which is consistent with their formation in the presence of $\mathrm{NaOCl}$ solution $(\mathrm{pH} \mathrm{12})$ during artificial ageing experiments. These compounds seemed to be formed 
simultaneously but the visual aspect of the samples changed during ageing experiments, showing different steps and colors.

Corderoite needs chlorine to be always available as a reagent to be stable. In the cases of the cyclic system, the potential is higher than for the closed system and chlorine is not the predominant species, which, according to Pourbaix diagrams, could explain the disappearance of corderoite after some time of ageing in this system. Moreover, when $\alpha$-HgS is in the presence of chlorine predominant, it cannot be stable and transforms into corderoite for low quantities of $\mathrm{ClO}_{(\mathrm{g})}$ and calomel for higher quantities. It appears also that corderoite is an intermediate product in the reaction of formation of calomel from $\alpha$-HgS.

The aim of the artificial ageing performed with mercury sulfide samples was to understand the alteration of cinnabar (or vermilion). The different compounds formed during these experiments are in agreement with those detected on historical fragments and those expected from thermodynamic studies.

The mapping of cross-sections obtained from the artificially aged samples seemed to reveal a multi-layered structure similar to the ones observed on altered works of art, with mercury chloride compounds on top of red mercury sulfide layers and sulfates at the surface of the samples. Equilibria proposed to explain the formation of calomel and corderoite from the reaction of red mercury sulfide with $\mathrm{ClO}_{(\mathrm{g})}$ showed the formation of sulfate ions, which is consistent with the presence of sulfates on the surface of the degraded samples even in closed systems and on the resin next to the pellets. When the pellets originally contain $\mathrm{Ca}$, calcium sulfates are identified, similarly to what was observed on the surface of some degraded frescoes.

Concerning the visual aspect of the degradation of red mercury sulfide, the different compounds detected on the pellets and on historical paintings (calomel, corderoite, kenhsuite, gypsum) explain the white/purple colors observed, but not the black one.

In the case of Pompeian samples, it has been proposed that the black color could be due to dust, trapped into gypsum during its crystallization. ${ }^{\mathbf{1 4}}$ This hypothesis is only plausible for original works of art, especially for those exposed outdoors, and not for our model samples aged in sealed tubes. Besides, no dust particles were observed during analyses performed on original altered samples.

As mentioned in the introduction, metacinnabar has long been considered to be the main responsible for the blackening of red cinnabar. Here, it was not detected in any of the altered samples; however it could be present in the form of small particles, perhaps of nanometric dimensions and possibly not well crystallized. Besides, the XRD pattern of $\beta$-HgS shows only a few peaks, the most intense (at $d=3.37675 \AA$ ) of which is strongly overlapping with the most intense peak of cinnabar $(d$ $=3.36013 \AA$ ). Accordingly, the identification of $\beta$ - $\mathrm{HgS}$ in a matrix of $\alpha-\mathrm{HgS}$ is not straightforward and the presence of traces of $\beta-\mathrm{HgS}$, even if not detected, cannot be excluded.

The black color of degraded cinnabar could also be explained by the presence of metallic mercury $\left(\mathrm{Hg}^{0}\right)$. As mentioned in the introduction, this hypothesis has already been proposed by Keune et al. ${ }^{12}$ In the study carried out by Da Pieve et al. ${ }^{18}$ theoretical spectroscopic results showed that none of the minerals identified as degradation compounds on mercury sulfide samples is intrinsically gray or black. They proposed the presence of elemental mercury as a by-product of the photoinduced mechanism that causes the darkening of the paintings. As shown in our simulations, in some conditions, the formation of $\mathrm{Hg}(0)$ from $\mathrm{HgS}$ is thermodynamically favorable. Recently, the formation of metallic mercury from $\mathrm{HgS}$ by the joint action of light and chloride ions has been experimentally demonstrated by means of electrochemical methods. ${ }^{46,47}$ While electrochemistry is a very efficient way to detect metallic mercury, it is unfortunately not directly applicable to the study of tiny original painting fragments. Indeed, the non-invasive identification of metallic mercury with micrometric resolution and in the presence of a complex mixture of different $\mathrm{Hg}$ compound $\mathrm{s}^{48}$ is not easy to accomplish. Elemental analyses are not useful in this case while XRD patterns are expected not to show well defined and intense peaks but a diffuse background instead. TEM analyses, requiring an ultrahigh vacuum sample environment, might result in dehydration of the sample and potential loss of volatile $\mathrm{Hg}$ species, in particular of metallic mercury $\mathrm{Hg}(0)$ (with potential damage to both the sample and the instrument). XAS measurements can be considered, but (i) Hg-compounds have already shown a susceptibility to beam damage (not observed at $\mathrm{Cl}$ and $\mathrm{S}$ K-edge) while (ii) liquid and disordered $\mathrm{Hg}(0)$ does not present strong XAS features making its identification in a mixture of other crystallized $\mathrm{Hg}$-species difficult. As proposed by Jew et al. ${ }^{48}$ cryo-analyses are a good strategy to crystallize metallic mercury and increase the probability of detecting it via XAS or XRD. Cryo-environments are seldom used for analysis of cultural heritage materials, but in the present case, it would offer an additional opportunity to detect $\mathrm{Hg}(0)$ in painting cross-sections with micrometric resolution.

Interestingly, the findings in this paper will be pertinent as well in the Environmental Sciences field. Indeed, some decontamination processes for mercury pollution are aimed at the formation of mercury sulfide, and rely on a hypothetic long term stability of cinnabar. ${ }^{49-51}$ Consequently, the understanding of the stability of this phase in oxidizing conditions and in the presence of chlorine is relevant also outside the cultural heritage field.

\section{Acknowledgements}

The authors gratefully acknowledge the ESRF for granting beamtime under proposal no. EC720. Michel Dubus is thanked for providing precious advices concerning ageing protocols. This research was supported by Belgian Science Policy project S2-ART (BELSPO S4DA), the GOA "SOLARPAINT" (Research Fund University of Antwerp, Belgium) and FWO (Brussels, Belgium) projects no. G.0C12.13, G.0704.08 and G.01769.09.

\section{References}

1 R. J. Gettens, Stud. Conserv., 1972, 17, 45-69.

2 Pliny the Elder, Naturalis Historia, CA, 1977-1979, vol. XXXIII.

3 R. M. Dreyer, Notes and News, 1939. 
4 R. Grout and A. Burnstock, Zeitschrift, 2000, 15-22.

5 R. S. Davidson and C. J. Willsher, Dalton, 1981, 833-835.

6 J. K. Mc Cormack, Miner. Deposita, 2000, 35, 796-798.

7 R. J. Gettens, R. L. Feller and W. T. Chase, Artists' Pigm., 1993, 2, 159-182.

8 C. Miguel, J. V. Pinto, M. Clarke and M. J. Melo, Dyes Pigm., 2014, 302, 210-217.

9 P. Ballirano, M. Botticelli and A. Maras, Eur. J. Mineral., 2013, 25, 957-965.

10 M. Bacci, M. Picollo, S. Porcinai and B. Radicati, Thermochim. Acta, 2000, 365, 25-34.

11 P. Ropret, R. Zoubek, A. Sever Skapin and P. Bukovec, Mater. Charact., 2007, 58, 1148-1159.

12 K. Keune and J. J. Boon, Anal. Chem., 2005, 77, 4742-4750.

13 M. Spring and R. Grout, Nat. Gall. Techn. Bull., 2002, 23, 5061.

14 M. Cotte, J. Susini, N. Metrich, A. Moscato, C. Gratziu, A. Bertagnini and M. Pagano, Anal. Chem., 2006, 78, 74847492.

15 M. Cotte, J. Susini, V. A. Solé, Y. Taniguchi, J. Chillida, E. Checroun and P. Walter, J. Anal. At. Spectrom., 2008, 23, 820-828.

16 M. Radepont, W. De Nolf, K. Janssens, G. Van der Snickt, Y. Coquinot, L. Klaassen and M. Cotte, J. Anal. At. Spectrom., 2011, 26, 959-968.

17 A. Santoro, R. Terzano, G. Blo, S. Fiore, S. Mangold and P. Ruggiero, J. Synchrotron Radiat., 2010, 17, 187-192.

18 F. Da Pieve, C. Hogan, D. Lamoen, J. Verbeeck, F. Vanmeert, M. Radepont, M. Cotte, K. Janssens, X. Gonze and G. Van Tendeloo, Phys. Rev. Lett., 2013, 111, 208302.

19 T. Okita, K. Kaneda, T. Yanaka and R. Sugair, Atmos. Environ., 1974, 8, 927-936.

20 G. Thomson, Butterworth-Heinemann Edition, 2nd edn, 1986, p. 153.

21 M. Radepont, Understanding of chemical reactions involved in pigment discoloration, in particular in mercury sulfide (HgS) blackening, PhD thesis from Universiteit Antwerpen and Université Pierre et Marie Curie, 2013, 82-85 and 9293, https://tel.archives-ouvertes.fr/tel-00805147/.

22 S. Bergeon, Science et patience ou la restauration des peintures, RMN, 1990, p. 17.

23 C. Paolini and M. Faldi, Glossario delle techniche artistiche e del restauro, Edizioni Palazzo Spinelli, 2000, p. 307.

24 Restoration report C2RMF no. 9684, Caporali « Annonciation », 1970.

25 Restoration report C2RMF no. P3, Fra Angelico « Couronnement de la Vierge ", 1964.

26 Restoration report C2RMF no. P158, Retable de Thouzon, 1963.
27 Restoration report C2RMF no. P248, Le Valentin « Réunion dans un cabaret », 1968.

28 N. P. Brandon, P. A. Francis, J. Jeffrey, G. H. Kelsall and Q. Yin, J. Electroanal. Chem., 2001, 497, 18-32.

29 M. Svensson, A. Düker and B. Allard, J. Hazard. Mater., 2006, 136, 830-836.

30 G. A. Parks and D. K. Nordstrom, Chemical Modeling in Aqueous Systems, 1979, pp. 339-352.

31 E. H. Carlson, J. Cryst. Growth, 1967, 1, 271-277.

32 K. Paquette and G. Helz, Water, Air, Soil Pollut., 1995, 80, 1053-1056.

33 X. Zhou, K. Zeng, W. Qi, X. Yang and K. Wang, J. Ethnopharmacol., 2010, 131, 196-202.

34 N. Salvado, S. Buti, J. Nicholson, H. Emerich, A. Labrador and T. Pradell, Talanta, 2009, 79, 419-428.

35 N. Salvado, S. Buti, A. Labrador, G. Cinque, H. Emerich and T. Pradell, Anal. Bioanal. Chem., 2010, 399, 3041-3052.

36 A. Duran, J. Castaing and P. Walter, Appl. Phys. A, 2010, 99, 333-340.

37 http://www.esrf.eu/computing/scientific/FIT2D.

38 A. Somogyi, M. Drakopoulos, L. Vincze, B. Vekemans, C. Camerani, K. Janssens, A. Snigirev and F. Adams, X-Ray Spectrom., 2001, 30, 242-252.

39 http://xrdua.ua.ac.be.

40 J. Susini, M. Salome, B. Fayard, R. Ortega and B. Kaulich, Surf. Rev. Lett., 2002, 9, 203-211.

41 V. A. Sole, E. Papillon, M. Cotte, P. Walter and J. Susini, Spectrochim. Acta, Part B, 2007, 62, 63-68.

42 J. J. Ezrati, Théorie, technique et technologie de l'éclairage muséographique, Editions AS, 2002, p. 117.

43 E. E. Foord and P. Berendsen, Am. Mineral., 1974, 59, 652655.

44 J. K. McCormack and F. W. Dickson, Can. Mineral., 1998, 36, 201-206.

45 M. Maguregui, U. Knuutinen, I. Martinez-Arkarazo, K. Castro and J. M. Madariaga, Anal. Chem., 2011, 83, 3319-3326.

46 W. Anaf, K. Janssens and K. De Wael, Angew. Chem., 2013, 125, 1-5.

47 W. Anaf, S. Trashin, O. Schalm, D. van Dorp, K. Janssens and K. De Wael, Anal. Chem., 2014, 86, 9742-9748.

48 A. D. Jew, C. S. Kim, J. J. Rytuba, M. S. Gustin and G. E. Brown Jr, Environ. Sci. Technol., 2010, 45, 412-417.

49 C. S. Kim, J. J. Rytuba and G. E. Brown Jr, Appl. Geochem., 2004, 19, 379-393.

50 M. O. Barnett, R. R. Turner and P. C. Singer, Appl. Geochem., 2001, 16, 1499-1512.

51 R. Terzano, A. Santoro, M. Spagnuolo, B. Vekemans, L. Medici, K. Janssens, J. Göttlicher, M. A. Denecke, S. Mangold and P. Ruggiero, Environ. Pollut., 2010, 158, 2702-2709. 